\title{
Desigualdades e Interações de Classe Social na Saúde no Brasil ${ }^{*}$
}

\author{
José Alcides Figueiredo Santos \\ Professor do Programa de Pós-Graduação em Ciências Sociais da Universidade Federal de Juiz de Fora (UFJF). \\ Juiz de Fora, MG. Brasil. \\ E-mail: josealcides@yahoo.com.br, https:/ / orcid.org/0000-0003-2606-7150
}

E ste trabalho atualiza, aprofunda e explora novas direções numa linha de investigação sobre os condicionamentos de classe social na distribuição da saúde no Brasil usando dados da Pesquisa Nacional de Saúde (PNS) 2013. Os estudos empreendidos anteriormente sobre a realidade brasileira revelaram que há um importante ganho analítico e empírico no uso da noção sociológica de classe social para abordar a desigualdade de saúde no confronto com os indicadores mais convencionais de posição socioeconômica, tais como renda e educação. A noção é igualmente relevante para entender o papel de categorias de status social, como raça, na operação da desigualdade de saúde. Além disso, o emprego de categorias de classe conceitualmente unívocas sugere elementos para o entendimento das desigualdades observadas (Figueiredo Santos, 2011a, b e c).

Os fundamentos mais gerais desta iniciativa reportam-se aos fatos bem estabelecidos e reconhecidos da desigualdade socioeconômica na distribuição da saúde e da mortalidade dentro das populações nas sociedades contemporâneas (Marmot, Kogevinas e Elston, 1987; Marmot, Bobak e Smith, 1995; Elo, 2009). Regra geral é bastante forte a padronização das desigualdades observadas em saúde; fala-se mesmo na emergência de um tipo de "nexo invariante" - quanto pior a posição social, tanto pior a saúde ${ }^{1}$. A posição socioeconômica estrutura ou influencia o grau de exposição aos principais fatores de risco e a progressão das doenças: pessoas de estrato socioeconômico inferior ${ }^{*}$ Este artigo beneficiou-se de um auxílio de pesquisa do Conselho Nacional de Desenvolvi-
mento Científico e Tecnológico (CNPq).

DADOS, Rio de Janeiro, vol.63(1):e20180104, 2020.

http://dx.doi.org/10.1590/001152582020203 
tendem a estar em desvantagem no amplo conjunto de fatores que medeiam a relação entre as condições sociais e a doença (House et al., 1994 e 2005; House e Williams, 2000; Lahelma, 2010).

As condições sociais são "causas fundamentais" da saúde e da doença porque influenciam a exposição a múltiplos fatores de risco e oferecem acesso a importantes recursos que podem sustentar a saúde ou conduzir a tratamentos terapêuticos, atuando como fatores subjacentes que colocam as pessoas ao "risco de riscos". Elas condicionam o acesso a recursos de natureza flexível e aplicáveis a diferentes situações que podem ser usados para evitar riscos ou minimizar as consequências da doença quando ela ocorre.

A associação entre condições sociais e doença se reproduz dinamicamente no tempo; mantém-se quando mudam as doenças, os riscos e os tratamentos por meio da substituição seletiva dos mecanismos mediadores mais próximos que levam à ocorrência da doença (Link e Phelan, 1995 e 2010; Phelan e Link, 2013). As desigualdades de recursos mobilizáveis para a saúde, a seletividade social na exposição aos riscos, a constituição social das disposições ou preferências de saúde, as discrepâncias nos modos como as instituições processam os indivíduos e as assimetrias dos transbordamentos (spillovers) de custos ou benefícios dos processos fazem com que as condições sociais representem um tipo de metamecanismo responsável pelo modo como mecanismos específicos e variados são continuamente gerados na vida social e no transcurso do tempo de tal modo a ser preservada, de forma duradoura, a direção da associação entre posição socioeconômica e saúde (Lutfey e Freese, 2005 e 2011).

A ênfase na relação abrangente entre estrutura social e saúde destaca a importância do trabalho conceitual e de mensuração da posição socioeconômica das pessoas. Um retorno ao conceito sociológico de classe social pode informar e estruturar melhor o entendimento científico das desigualdades de saúde (Williams e Collins, 1995:377). A investigação da desigualdade em saúde pode ganhar em profundidade ao usar uma medida de posição socioeconômica enraizada teoricamente e ao promover a interpretação dos resultados de acordo com essa base teórica (Galobardes et al., 2006:48). 
Os indicadores convencionais são bastante úteis para descrever os padrões observáveis e para finalidades de previsão ou de extrapolação do que se espera encontrar. Entretanto, mostram-se débeis para explicar o que é observado, pois não têm uma base teórica clara, ou então permitem justificativas teóricas múltiplas e mesmo contraditórias. As inconsistências conceituais que esses indicadores possuem têm dificultado a superação dos limites da simples descrição de padrões. Já a adoção preferencial de medidas de posição socioeconômica de sólida base teórica estimula um progresso mais rápido nos ganhos de entendimento da desigualdade em saúde (Bartley et al., 1999; Bartley, 2017). O conceito sociológico de classe social, além disso, pode cobrir aspectos da variação social na saúde que não são capturados pelas medidas convencionais de posição socioeconômica (Muntander et al., 2003). Um enfoque relacional de classe favorece o entendimento da geração, da distribuição e da persistência das trajetórias diversificadas que de modo convergente conduzem ao estabelecimento da desigualdade em saúde (Krieger, Williams e Moss, 1997:356-7).

Existe um grande corpo de literatura sociológica e de epidemiologia social sobre a influência independente da posição socioeconômica na distribuição desigual da saúde, embora bem menos de classe social. A noção de classe social apresenta algumas vantagens em comparação aos indicadores convencionais de status socioeconômico, tendo em vista que pretende delimitar teoricamente os determinantes de resultados em vez de priorizar apenas o retrato descritivo dos resultados distributivos em si. Sua noção e mensuração baseiam-se em teoria sociológica e abordam os processos sociais. Por isso mesmo, o conceito é melhor para fins explicativos dos determinantes sociais ou "não naturais" da doença, já que permite uma melhor especificação das circunstâncias, dependências e exclusões que criam problemas de saúde entre os grupos sociais. Além de refletir os elementos comuns, a noção traz aspectos adicionais e mais diversificados em comparação com os indicadores convencionais: o emprego caracteriza o que alguém tem (ativos ou recursos) e o que essa pessoa faz (prática social e relações entre atores); além disso, o emprego está associado à educação (como insumo para acesso e desempenho do trabalho) e à renda (como resultado do trabalho). 
A categorização social fornece uma delimitação mais real, socialmente identificável e mais ampla em termos dos processos envolvidos. A categoria "gerente", por exemplo, tem um sentido sociológico bem mais claro do que uma referência à décima parte superior da distribuição de renda. A noção de classe permite uma melhor especificação e contextualização dos recursos valiosos, flexíveis e polivalentes que geram benefícios materiais e de saúde. Indicadores convencionais não estão claramente associados às características típicas da sociedade capitalista e, portanto, não refletem bem os processos sistêmicos, institucionais, organizacionais, ao nível micro (agência), que estabelecem e reproduzem a desigualdade nessa sociedade.

Os condicionamentos estruturais das chances de vida, inscritos em vários níveis da vida social, não são facilmente alteráveis e afetam a distribuição da saúde. Veja-se o caso mais recente do Reino Unido, em que as desigualdades de classe de saúde se ampliaram, para a maioria das medidas, mesmo depois de políticas para a sua redução pelo governo trabalhista de 1997 a 2010 (Smith, Hill e Bramda, 2016). Além disso, em termos contextuais, no período mais recente a sociedade brasileira esteve submetida a uma série de processos subjacentes que podem afetar potencialmente os resultados de saúde e sua distribuição populacional. As alterações mais características, porém com ritmos, intensidades e desdobramentos diferenciados, envolveram a estrutura do emprego, o mercado de trabalho, as condições de vida, a distribuição da renda, pelo menos abaixo do topo dos $5 \%$ mais ricos, a expansão educacional, os desequilíbrios territoriais, a seguridade social, o acesso ao sistema público de saúde e a cobertura dos planos privados de saúde. Utiliza-se um modelo de classe baseado no emprego. São também considerados fatores independentes, porém associados aos empregos, como insumo (educação) ou resultado (renda), com a finalidade de ver as consequências diferenciadas desses processos para a distribuição da saúde entre os grupos sociais.

O papel do conceito de classe no entendimento da desigualdade de saúde pode ser potencializado com a sugestão dos mecanismos que projetam a sua influência. A noção de classe baseada no emprego valoriza os diversos fatores associados às relações e condições de trabalho. Empregos condensam diferentes feixes de direitos e poderes sobre recursos valiosos que afetam a prática social e as relações entre os agentes; estão associados no mundo do trabalho e em outros âmbitos da vida social aos fatores materiais, ambientais, comportamentais e 
psicossociais que possuem implicações para a saúde. Relacionam-se às desigualdades de recursos mobilizáveis para a saúde, à seletividade social na exposição aos riscos, à constituição social de preferências de saúde e às discrepâncias nos modos como as instituições de saúde processam os indivíduos. Por fim, a trajetória dos ocupantes dos empregos atuais, tendo em vista as relações entre origem e destino social, pode incorporar ou refletir em parte fatores pretéritos que possuem efeito cumulativo no desenvolvimento pessoal.

A maneira de entender a desigualdade social tem implicações importantes para o estudo da desigualdade de saúde. As desigualdades são de diferentes tipos e podem influenciar a saúde de diferentes modos (Bartley, 2017:11). A noção de classe social baseada no emprego articula também as dimensões educação e renda, visto que a primeira funciona como recurso posicional de acesso a empregos e a segunda é um fluxo derivado do emprego. As duas aproximam-se ao captarem aspectos da estratificação social subjacente, porém o fazem em diferentes momentos e níveis, assim como envolvendo processos ou mecanismos diferentes. Não devem, porém, ser vistas como intercambiáveis, pois possuem efeitos diferenciados na saúde; ademais as correlações entre elas não são tão fortes a ponto de justificar a sua equiparação (Braveman et al., 2005)².

O artigo está organizado em torno de quatro aspectos e interesses de conhecimento. O estudo almeja analisar os efeitos específicos na saúde das divisões de classe social e supõe que o controle de recursos que geram mais ganhos materiais, ou que são de distribuição mais desigual, ou então de mobilização mais flexível e polivalente nos contextos sociais podem gerar mais vantagens e discrepâncias de saúde.

Aborda-se a evolução da desigualdade socioeconômica de saúde no Brasil na década que vai de 2003 a 2013 utilizando indicadores convencionais de décimos de renda e níveis educacionais para mapear a trajetória temporal da desigualdade por ter se mostrado inviável o uso da mensuração de classe social devido às mudanças na classificação ocupacional aplicada pelo Instituto Brasileiro de Geografia e Estatística (IBGE) na Pesquisa Nacional de Saúde (PNS) 2013. Na relação focal entre posição socioeconômica e saúde no período investigado exploram-se possibilidades e dimensões diferenciadas que a educação e a renda das pessoas podem captar e expressar. 
O trabalho propõe-se a escrutinar a associação da variável auto-avaliação da saúde, usada para mensurar os padrões de classe social de desigualdade de saúde, com um conjunto relevante de fatores de risco e comprometimentos da saúde. Almeja-se com isso entender melhor o status dessa variável dependente chave nos estudos de desigualdade de saúde e sua capacidade de representar fatores mais amplos associados ao estado de saúde das pessoas. Neste processo procura-se avaliar a contribuição dos fatores em questão para a desigualdade de saúde observada.

O estudo envereda na parte final por uma análise dos efeitos interativos entre classe social e determinados fatores relevantes associados à saúde. Renda e educação são indicadores socioeconômicos de destaque que tanto representam o que é importante quanto importam para a saúde. Busca-se entender em que medida os efeitos positivos na saúde dos ganhos obtidos nesses fatores possam ser afetados pelos contextos de classe social. Na consideração dos efeitos interativos projeta-se adicionalmente a ideia de que os efeitos possam ser diferentes a depender da aproximação das categorias em relação ao "teto" factível de saúde boa existente num dado momento. Estimam-se igualmente os efeitos interativos entre classe social e doença crônica. A prevalência de doença crônica é naturalmente um fator debilitante da saúde individual e populacional. Sabe-se do mesmo modo que as categorias privilegiadas possuem vantagens que lhes permitem diminuir as implicações deletérias ou a progressão mais danosa dos problemas de saúde. Tenta-se então aferir e entender possíveis discrepâncias de classe social no impacto da doença crônica no estado de saúde percebido pelas pessoas.

\section{MÉTODOS}

Variável dependente. $\mathrm{O}$ estudo focaliza prioritariamente a existência de discrepâncias de classe social na distribuição da autoavaliação do estado de saúde da pessoa. Esse indicador possui a vantagem de capturar a saúde média dos grupos da população em vez da prevalência de condições específicas ou de alto risco. Além do mais, mostra-se associado a múltiplos fatores sociais de risco à saúde e é útil para as necessidades de avaliação e intervenção de saúde pública (Borrell et al., 2004:1872). A avaliação geral pelo indivíduo do seu estado de saúde é uma medida que pode ser aplicada e servir para aferir riscos à 
saúde em diferentes estágios da vida. Representa a medida de estado de saúde mais acessível, abrangente e informativa em estudos populacionais, oferecendo o benefício de capturar dimensões da saúde que não são apreendidas por questões mais detalhadas e dirigidas (Jylha, 2009:313; Jylha, 2011). Tais características fazem dessa variável dependente a opção prioritária para a finalidade de demonstrar e avançar no entendimento dos padrões de desigualdade de saúde dentro da população.

A autoavaliação do estado de saúde foi tratada como uma variável dicotômica diferenciando-se o estado de saúde "não bom" (categoria designada), que reúne as respostas "ruim", "muito ruim" e "regular", em contraste com o estado de saúde definido como "bom" ou "muito bom" (categoria de referência) ${ }^{3}$. O uso da variável dependente autoavaliação de forma dicotômica é o procedimento padrão aplicado na grande maioria dos estudos internacionais e nacionais. Casos mais recentes são os estudos comparativos internacionais da European Commission (2013) e de Prag e Subramanian (2017) e do caso brasileiro com dados da PNS (Szwarcwald et al., 2016). Os modelos logísticos ordinais agregam dificuldades de complexidade, grande variedade e validação de pressupostos. Nos poucos estudos mais qualificados que comparam ambos os modelos os resultados substantivos tendem a não divergir. Além de facilitar a interpretação, a variável dicotômica ajuda a evitar a violação dos pressupostos associados aos modelos ordinais (Warren e Hernandez, 2007:349). Estudo de desigualdade de saúde com dados ingleses longitudinais mensurados em quatro diferentes idades demonstra que o recorte dicotômico escolhido (saúde boa e não boa) não compromete a obtenção de resultados válidos em termos de tamanho e significância dos efeitos principais, tipos de associação e efeitos interativos, quando comparados com diferentes modelos estatísticos que incorporam a natureza ordenada da autoavaliação da saúde (Manor, Matthews e Power, 2000). Optou-se adicionalmente por esse recorte visando não focalizar basicamente o grupo relativamente menor de pessoas com saúde mais deteriorada. Em termos estatísticos, variáveis dependentes com casos mais extremos e menos casos geram, respectivamente, questões de seletividade e de imprecisão das estimativas, em particular quando são usados termos interativos e regressão logística. Além disso, em termos de saúde pública é melhor conhecer as situações negativas no seu estágio inicial. 
Na variável dependente relativa ao estado de saúde, quando aplicada ao conjunto dos moradores, foi "corrigida" a discrepância entre a declaração dada por outro membro do domicílio (variável J001) e a dada pelo próprio morador aleatoriamente selecionado em variável similar que integra esta parte principal do questionário (variável N001). Na análise das mudanças temporais a variável não foi "corrigida" em 2013, pois não é possível alteração similar para os anos anteriores.

O estudo usou as Pesquisas Nacionais por Amostra de Domicílios (PNADs) de 2003 e 2008 cujos questionários possuem um suplemento de Saúde. A PNAD adota um plano amostral estratificado e conglomerado com um, dois ou três estágios de seleção, a depender do estrato. Os dados de 2013 são oriundos da PNS, que segue o desenho amostral de conglomerados da Amostra Mestra das Pesquisas Domiciliares do IBGE. Utilizaram-se em particular os dados relativos a todos os moradores do domicílio, parte que dá continuidade ao Suplemento Saúde da PNAD; na parte relativa a fatores de risco e doenças, recorreu-se ao questionário individual, respondido por um morador de 18 anos ou mais do domicílio, selecionado com equiprobabilidade entre todos os residentes elegíveis.

Variáveis independentes. A noção de classe está representada por uma tipologia neomarxista adaptada à realidade nacional (Wright, 1997; Figueiredo Santos, 2005, 2010 e 2014). A tipologia de classes original teve que ser totalmente reconstruída ao nível operacional, mantidos os fundamentos conceituais e os critérios orientadores, pois a PNS 2013 adotou uma nova classificação ocupacional, denominada COD, ajustada à nova Classificação Internacional Uniforme de Ocupações (CIUO-08) da Organização Internacional do Trabalho (OIT), porém não equivalente à Classificação Brasileira de Ocupações (CBO-Domiciliar) da PNAD Tradicional. Além disso, devido às lacunas de indicadores importantes relativos às categorias de empregadores (número de empregados) e autônomos (informações do empreendimento) foram adotados critérios substitutos para diferenciar as categorias de capitalistas versus pequenos empregadores, autônomos com ativos versus autônomos precários, autônomos agrícolas versus agrícolas precários, baseados em diferenciações internas de décimos de renda. A variável independente principal, classe social, envolve uma sequência de várias transformações em que se desagrega o "status" do emprego. Foram criadas duas versões da tipologia indo da forma desenvolvida a uma 
solução compacta composta de cinco agrupamentos de classe. No anexo retratam-se as soluções originais e os ajustes que tiveram que ser feitos para adequar a tipologia aos dados disponíveis na PNS 2013.

A variável idade foi mensurada ao nível intervalar sendo as estimativas restritas à população adulta de 18 a 64 anos. A variável gênero foi incluída de forma binária. Foram construídas três categorias para mensurar a variável raça ou cor agregando branco e amarelo na categoria omitida, pardo e indígena em outra e preto em separado, pois amarelo e indígena representam proporções ínfimas de casos. A variável região diferencia Sudeste, Sul, Nordeste, Centro-Oeste e Norte. Distingue-se o ambiente rural e urbano. A dimensão e centralidade urbana são captadas pela diferenciação entre capital e interior. Na comparação temporal 2003-2013 controla-se por Região Metropolitana ou não, pois a informação sobre capital é exclusiva da PNS 2013. Por fim, controla-se pelo informante da variável dependente de estado de saúde dos moradores do domicílio.

A variável binária denominada "desconforto mental", distinta do diagnóstico de depressão (questão Q092 da PNS), mede a presença ou reconhecimento pelo entrevistado de alguma sensação de incômodo, desconforto, inquietação, perturbação ou problema de ordem psicológica nas duas últimas semanas conforme as questões N011 a N018 da PNS. A variável binária "discriminação" mede se a pessoa já se sentiu discriminada ou tratada pior por algum motivo no atendimento de saúde com base nas questões X02501 a X02510 da PNS. A variável binária "tabagismo" mede se atualmente a pessoa fuma algum produto do tabaco (questão P050 da PNS). A variável binária "sedentarismo" mede se a pessoa praticou ou não algum exercício físico ou esporte nos últimos três meses (questão P034 da PNS). A variável binária "isolamento familiar" mede se a pessoa se sente ou não à vontade para falar de tudo com membro familiar (questão M014 da PNS). A variável binária "doença crônica" mede se a pessoa já teve diagnóstico médico de alguma doença crônica, física ou mental, entre os 13 itens cobertos pelo questionário da PNS. A variável binária "dificuldade de locomoção" mede se a pessoa tem ou não alguma dificuldade para se locomover (questão N003 da PNS).

Modelos. A variável dependente formada por categorias coloca o problema da escolha do modelo estatístico mais adequado. Os modelos logísticos que usam medidas baseadas em log-odds ratios ou odds 
ratios têm tido sua capacidade de gerar coeficientes que sejam adequadamente comparáveis entre grupos questionada (Mood, 2010). No modelo logit a variância do erro, por não ser observável, tem de ser fixada para o modelo ser identificado. A heterogeneidade não observada afeta o tamanho dos coeficientes logit mesmo se a variável independente e o termo de erro não estiverem correlacionados. Os modelos não podem separar as diferenças entre os grupos das diferenças na dispersão do erro latente. Entre as alternativas discutidas sugerem-se estimar as discrepâncias entre os grupos na variável dependente binária sob a forma de probabilidades preditas e efeitos marginais médios (average marginal effects, AME). A opção tem a vantagem adicional de permitir interpretação fácil e intuitiva: corresponde simplesmente a um efeito médio na probabilidade de um resultado. Evita-se a não linearidade do modelo ao calcular a média de todos os efeitos na variável dependente e o efeito aditivo na probabilidade é expresso em um único coeficiente (Best e Wolf, 2015). Todas as estimativas com intervalos de confiança de $99 \%$ foram ajustadas ao desenho complexo do plano amostral da PNS 2013 com o comando soy do programa Stata. As probabilidades preditas foram estimadas pelo margins e convertidas em gráficos pelo marginsplot do Stata. Foi usado o procedimento mlincom para testar a significância estatística das diferenças encontradas entre as categorias (Long e Freese, 2014). Os coeficientes da regressão logística são usados para calcular as probabilidades preditas atribuindo a todos a mesma condição e se ajustando à distribuição observada das outras variáveis no modelo. As probabilidades preditas expressam uma média ponderada que reflete a distribuição das variáveis confundidoras na população alvo (Muller e MacLehose, 2014). As probabilidades preditas foram calculadas usando os valores observados das variáveis de controle para cada caso na amostra, em vez de colocar as variáveis em seus valores médios. Estimam-se efeitos da média dos casos, com a finalidade de se obter um efeito médio na população, e não um efeito para o caso médio (Hanmer e Kalkan, 2013). Nas estimativas feitas para os subgrupos da população os resultados são ajustados para as diferenças entre os grupos nas respectivas distribuições das variáveis independentes. $\mathrm{O}$ ajustamento para as diferenças de atributos relevantes entre os grupos permite inferir de forma menos ambígua que as diferenças observadas entre os grupos seriam atribuíveis ao pertencimento de grupo. 
As discrepâncias absolutas e as proporcionais nas probabilidades foram calculadas pelo comando margins do Stata usando as opções $d y d x$ e eydx e depois transformadas em gráficos pelo marginsplot. A opção $d y d x$ calcula as diferenças aditivas absolutas na probabilidade para a mudança de uma unidade da variável independente. Para variáveis categóricas calcula as diferenças discretas em relação à categoria de base. A opção eydx estima a semielasticidade ou mudança proporcional no logaritmo do resultado (Y) para a mudança de uma unidade da variável independente. Nas variáveis independentes categóricas o efeito é computado como uma mudança discreta em relação à categoria de referência. Deve-se calcular o exponencial (ou antilog) para falar em aumento percentual usando a fórmula: $[\exp (\mathrm{Y})-1] * 100$. O aumento percentual diverge progressivamente da semielasticidade na medida em que ela se torna maior ${ }^{4}$.

Efeitos interativos expressam como um efeito muda sob a ação de outro fator. Corresponde a um efeito sobre um efeito. Os efeitos dependem do contexto ou condição (Kam e Franzese Jr., 2007). Supõe-se nas análises que os retornos (ou ganhos) de saúde da escolaridade ou renda possam variar a depender da posição de classe. O contexto afeta a conversão de um recurso em resultados. Supõe-se igualmente que as combinações dos efeitos de classe e doença crônica podem se associar a diferentes resultados na autoavaliação da saúde. $\mathrm{O}$ efeito deletério na saúde da doença crônica não teria a mesma intensidade, como refletida na autoavaliação da saúde, para o especialista e o trabalhador destituído. Todos os efeitos foram estimados usando termos interativos entre as variáveis envolvidas. O comando de pós-estimação margins do Stata calcula as probabilidades preditas e as diferenças entre as probabilidades removendo os constrangimentos de efeitos aditivos ou equivalentes e permitindo que os efeitos variem a depender do contexto.

\section{ESTIMATIVAS DOS EFEITOS SEM E COM AJUSTES}

Na Tabela 1 são apresentadas as estimativas para todos os moradores e o morador aleatoriamente sorteado que responde aos principais módulos do questionário. Os resultados estão apresentados como proporções. As diferenças absolutas na maioria das vezes são comentadas no texto como diferenças em pontos percentuais. Na descrição e interpretação dos resultados costuma-se estimar um modelo inicial, não ajustado ou minimamente ajustado, cujas diferenças observa- 
das refletem a situação das pessoas concretas que estão dentro dos grupos ou contextos. Optou-se pela estimativa de um modelo inicial controlado somente pelas variáveis idade e informante.

Tabela 1

Probabilidades Preditas de Não Ter Saúde Boa por Classe Social

Brasil, 2013

\begin{tabular}{lccccc}
\hline Posições de Classe & \multicolumn{2}{c}{ Moradores } & Dif. EA & \multicolumn{2}{c}{ Morador Sorteado } \\
\hline & Inicial & Ajustado & Razão & Inicial & Ajustado \\
Topo social & 0,103 & 0,120 & 1,348 & 0,120 & 0,139 \\
Capitalista & 0,081 & 0,107 & $1,202^{*}$ & 0,126 & 0,161 \\
Especialista autônomo (EA) & 0,070 & 0,089 & - & 0,079 & 0,102 \\
Gerente & 0,122 & 0,139 & 1,561 & 0,136 & 0,156 \\
Empregado especialista & 0,102 & 0,116 & $1,303^{*}$ & 0,119 & 0,134 \\
Pequeno empregador & 0,163 & 0,179 & 2,011 & 0,208 & 0,228 \\
Autônomo com ativos & 0,189 & 0,211 & 2,370 & 0,201 & 0,226 \\
Autônomo agrícola & 0,291 & 0,269 & 3,022 & 0,308 & 0,287 \\
Empregado qualificado & 0,162 & 0,166 & 1,865 & 0,179 & 0,181 \\
Supervisor & 0,162 & 0,188 & 2,112 & 0,154 & 0,182 \\
Trabalhador típico & 0,216 & 0,225 & 2,528 & 0,238 & 0,249 \\
Trabalhador elementar & 0,297 & 0,282 & 3,168 & 0,337 & 0,321 \\
Autônomo precário & 0,340 & 0,307 & 3,449 & 0,361 & 0,325 \\
Empregado doméstico & 0,340 & 0,312 & 3,505 & 0,384 & 0,348 \\
Agrícola precário & 0,445 & 0,341 & 3,831 & 0,465 & 0,357 \\
Trabalhador excedente & 0,312 & 0,296 & 3,325 & 0,351 & 0,334 \\
\hline
\end{tabular}

Fonte: Elaboração própria a partir dos microdados da PNS 2013.

* Diferença estatisticamente não significativa.

O maior contraste de classe constatado mostra que a probabilidade predita de um especialista autônomo não ter saúde boa é de somente $7 \%$, porém atinge $44 \%$ em alguém com emprego agrícola precário, ou seja, se multiplica por mais de seis vezes. Seguem-se no ordenamento da desvantagem, com probabilidade de $34 \%$, as categorias de autônomo precário e empregado doméstico que possuem pesos ponderáveis na estrutura social. Este quadro retrata o que se passa com as "pessoas concretas". A estimativa do efeito mais "puro" dos empregos demanda a agregação de mais controles, para remover a influência de outros fatores. As estimativas de efeitos ajustados visam delimitar o impacto independente ou mais puro dos empregos no estado de saúde que se distribui desigualmente na população. $\mathrm{O}$ modelo foi 
ajustado ou controlado pelas variáveis sexo, cor, idade, região, zona (rural ou urbana), dimensão e centralidade urbana (capital ou não), além de idade e informante. A ideia é estimar o efeito mais intrínseco do emprego ou posição de classe. As categorias mais privilegiadas que formam o topo social - capitalista, especialista autônomo, empregado especialista e gerente - regra geral apresentam diferenças entre si que não são estatisticamente significativas, ao nível de 99\%, excetuando a vantagem do especialista autônomo sobre o gerente. Criou-se uma categoria agregada do topo social composta de capitalista, especialista autônomo, empregado especialista e gerente, pois todos ostentam uma situação de saúde similar ou não diferenciada na sua significância estatística. Além disso, o expediente fornece uma opção de comparação demograficamente mais representativa.

Os principais contrastes de classe se mantêm no modelo ajustado. A probabilidade média ajustada de um especialista autônomo não ter saúde boa é de somente 8,9\%, porém atinge 34\% em alguém com emprego agrícola precário, ou seja, quase se multiplica por mais de quatro vezes, mesmo quando se removem os efeitos de residência e ambiente (nordeste, zona rural). No autônomo precário e empregado doméstico fica em $31 \%$, mostrando bastante força intrínseca, pois muda bem pouco após a introdução dos controles. Os dados para o morador sorteado confirmam o padrão encontrado. Em todos os grupos, exceto o supervisor, ele mostra um quadro pior de saúde em ambos os modelos.

As probabilidades de todas as categorias são comparadas com o especialista autônomo, que possui o melhor estado de saúde. Essa medida de desigualdade relativa mostra o quanto se está distante da realidade alcançada por esse grupo. Tem-se então como termo de comparação o melhor padrão médio efetivamente realizado para uma dada posição de classe. Em todas as posições destituídas de ativos, do trabalhador elementar para baixo, assim como no autônomo agrícola, a situação negativa de saúde excede em mais de $200 \%$ ao padrão encontrado no especialista autônomo. $\mathrm{O}$ trabalhador elementar, embora inclua um estrato agrícola, está numa situação menos negativa nesse agrupamento, o que pode sinalizar a diferença promovida pelo trabalho assalariado. O trabalhador típico, a categoria de maior densidade social, está numa situação intermediária e equidistante entre o empregado qualificado (técnico) e o trabalhador elementar (braçal). Nos contrastes entre as três categorias de assalariados não privilegiados constatam-se as implicações para a saúde das relações e condições de emprego diferenciadas. 


\section{EVOLUÇÃO DA DESIGUALDADE DE SAÚDE NA DÉCADA}

A adoção na PNS 2013 de uma classificação ocupacional bastante distinta da PNAD tradicional, usada atualmente na PNAD Contínua, inviabilizou a comparação temporal com os dados anteriores de 2003 e 2008 usando uma concepção e mensuração de classe social. A opção foi usar os indicadores mais convencionais de posição socioeconômica, níveis de educação e décimos de renda para analisar possíveis alterações na desigualdade de saúde. Considera-se a evolução temporal da probabilidade predita de não ter saúde boa ajustada por controles (Tabela 2). As comparações são feitas com os grupos que possuem o melhor estado de saúde apurando-se tanto diferenças absolutas quanto diferenças relativas. Visando manter a comparação entre os dois indicadores o indicador educacional é restrito aos que possuem renda do trabalho. Olha-se então para as pessoas que estão empregadas. Renda e educação são marcadores ou indicadores probabilísticos da circunstância socioeconômica (Bartley, 2017:25) e representam em certo sentido insumos ou resultados associados aos empregos. Além disso, possuem efeitos independentes, captando informação diferenciada que pode ser complementar.

Tabela 2

Probabilidades Preditas de Não Ter Saúde Boa por Níveis Educacionais e Diferença em Relação ao Superior Completo. Brasil, 2003-2013.

\begin{tabular}{lcccccccccc}
\hline Medidas & \multicolumn{3}{c}{ Probabilidade } & \multicolumn{1}{c}{ Var. } & \multicolumn{3}{c}{ Dif. Absoluta } & \multicolumn{3}{c}{ Dif. Relativa* } \\
\hline $\begin{array}{l}\text { Nível de } \\
\text { Escolaridade }\end{array}$ & 2003 & 2008 & 2013 & Década & 2003 & 2008 & 2013 & 2003 & 2008 & 2013 \\
Sem escolaridade & 0,273 & 0,296 & 0,340 & 1,245 & 0,190 & 0,200 & 0,210 & 2,289 & 2,083 & 1,611 \\
Fund. incompleto & 0,246 & 0,274 & 0,324 & 1,317 & 0,163 & 0,178 & 0,194 & 1,963 & 1,854 & 1,492 \\
Fund. completo & 0,195 & 0,219 & 0,289 & 1,482 & 0,112 & 0,123 & 0,159 & 1,349 & 1,281 & 1,223 \\
Médio incompleto & 0,193 & 0,216 & 0,249 & 1,290 & 0,110 & 0,120 & 0,119 & 1,325 & 1,25 & 0,915 \\
$\begin{array}{l}\text { Médio completo } \\
\text { Superior }\end{array}$ & 0,143 & 0,159 & 0,207 & 1,448 & 0,060 & 0,063 & 0,077 & 0,722 & 0,656 & 0,592 \\
$\quad$ incompleto & 0,114 & 0,121 & 0,178 & 1,254 & 0,031 & 0,025 & 0,048 & 0,373 & 0,260 & 0,369 \\
$\begin{array}{c}\text { Superior } \\
\text { completo }\end{array}$ & 0,083 & 0,096 & 0,130 & 1,566 & - & - & - & - & - & - \\
\hline
\end{tabular}

Fonte: Elaboração própria a partir dos microdados da PNS 2013.

* Diferença relativa: razão entre a diferença absoluta e o superior completo. 
Embora a restrição do estudo aos que possuem renda introduza uma seletividade, esta atua mais no sentido de subestimar a desigualdade, produzindo estimativas mais conservadoras ao excluir da amostra em particular pessoas menos saudáveis associadas a desvantagens socioeconômicas. $\mathrm{O}$ uso do indicador educacional é menos seletivo, porém menos comparável no tempo, pois os estratos educacionais mudam de tamanho por conta da expansão educacional e se tornam mais heterogêneos em fatores que afetam a saúde, como origem social, tipo de emprego, renda e outros. A renda representa um resultado temporal mais comparável, pois os décimos de renda não mudam de tamanho e mantêm a mesma posição relativa.

Tabela 3

Variação Temporal da Probabilidade Predita de Não Ter Saúde Boa por Região e Escolaridade Superior. Brasil, 2003-2013

\begin{tabular}{lcccccc}
\hline Nível & \multicolumn{3}{c}{ Superior Completo } & \multicolumn{3}{c}{ Nível Abaixo } \\
\hline Região & 2003 & 2013 & Var. & 2003 & 2013 & Var. \\
Norte & 0,119 & 0,182 & 1,529 & 0,271 & 0,340 & 1,255 \\
Nordeste & 0,109 & 0,187 & 1,716 & 0,252 & 0,348 & 1,381 \\
Sudeste & 0,071 & 0,103 & 1,451 & 0,175 & 0,213 & 1,217 \\
Sul & 0,102 & 0,119 & 1,167 & 0,202 & 0,241 & 1,193 \\
Centro-Oeste & 0,102 & 0,134 & 1,314 & 0,238 & 0,266 & 1,118 \\
Brasil & 0,088 & 0,134 & 1,523 & 0,209 & 0,263 & 1,258 \\
\hline
\end{tabular}

Fonte: Elaboração própria a partir dos microdados da PNS 2013.

Destaca-se em primeiro lugar uma piora para todos os grupos do quadro de saúde (Tabela 2). A probabilidade de ter saúde não boa eleva-se em $24,5 \%$ entre aqueles sem escolaridade e em $56,6 \%$ para quem tem curso superior completo. Aumentam as discrepâncias absolutas (subtração entre as probabilidades) de todos os grupos em relação ao superior completo o que reflete o patamar elevado em que estavam. Entretanto, as diferenças relativas diminuem, pois o quadro de saúde piora em maior grau para o superior completo do que para os demais grupos. A evolução da desigualdade por nível de escolaridade, sem o condicionante de possuir renda do trabalho, mostra uma tendência geral similar (dados não mostrados aqui). 
O quadro decorre em particular da evolução negativa do estado de saúde de quem tem curso superior completo nas regiões Norte e Nordeste (Tabela 3). A probabilidade predita de saúde não boa aumenta na década em $71,6 \%$ no Nordeste para quem tem superior completo, ao ir de 0,119 em 2003 para 0,182 em 2013. Em quem está abaixo de superior completo o aumento é de $38,1 \%$. Ocorre na região Norte a segunda maior elevação, da ordem de 52,9\%, quando a probabilidade sobe de 0,119 para 0,182 no grupo superior completo, enquanto a elevação é de $25,5 \%$ abaixo desse nível de escolaridade.

Tabela 4

Probabilidades Preditas de Não Ter Saúde Boa por Décimos de Renda e Diferença em Relação aos 10\% mais Ricos. Brasil, 2003-2013

\begin{tabular}{lcccccccccccc}
\hline Medidas & \multicolumn{3}{c}{ Probabilidade } & \multicolumn{2}{c}{ Var. } & \multicolumn{2}{c}{ Dif. Absoluta } & \multicolumn{3}{c}{ Dif. Relativa* } \\
\hline Décimos & 2003 & 2008 & 2013 & Década & 2003 & 2008 & 2013 & 2003 & 2008 & 2013 \\
Menor & 0,301 & 0,339 & 0,388 & 1,289 & 0,207 & 0,241 & 0,269 & 2,202 & 2,459 & 2,261 \\
& & & & & & & & & & \\
2o Décimo & 0,261 & 0,284 & 0,334 & 1,280 & 0,167 & 0,186 & 0,215 & 1,777 & 1,898 & 1,807 \\
3o Décimo & 0,247 & 0,253 & 0,293 & 1,186 & 0,153 & 0,155 & 0,174 & 1,628 & 1,582 & 1,462 \\
4 Décimo & 0,233 & 0,245 & 0,267 & 1,146 & 0,139 & 0,147 & 0,148 & 1,479 & 1,500 & 1,244 \\
5o Décimo & 0,219 & 0,223 & 0,247 & 1,278 & 0,125 & 0,125 & 0,128 & 1,330 & 1,276 & 1,076 \\
6o Décimo & 0,191 & 0,201 & 0,229 & 1,199 & 0,097 & 0,103 & 0,110 & 1,032 & 1,051 & 0,924 \\
7o Décimo & 0,178 & 0,179 & 0,217 & 1,219 & 0,084 & 0,081 & 0,098 & 0,894 & 0,827 & 0,823 \\
80 Décimo & 0,159 & 0,157 & 0,192 & 1,208 & 0,065 & 0,059 & 0,073 & 0,691 & 0,602 & 0,613 \\
9o Décimo & 0,137 & 0,141 & 0,161 & 1,175 & 0,043 & 0,043 & 0,042 & 0,457 & 0,439 & 0,352 \\
Maior & 0,094 & 0,098 & 0,119 & 1,266 & - & - & - & - & - & - \\
\hline
\end{tabular}

Fonte: Elaboração própria a partir dos microdados da PNS 2013.

* Diferença relativa: razão entre a diferença absoluta e o maior décimo ( $10 \%$ mais rico).

Ao estratificar a população em grupos de renda constata-se também que o estado médio de saúde piora para todos na década (Tabela 4). O aumento na proporção de saúde não boa é maior, nesta ordem de importância, nos dois décimos mais pobres, no meio da distribuição e no décimo mais rico. $\mathrm{O}$ divisor de renda mostra uma evolução negativa para privilegiados ou não, porém menor quando comparado ao divisor educacional. A probabilidade média do décimo mais rico sobe 
de 0,094 para 0,119 , ou $26,6 \%$ de aumento na década, bem inferior aos $52,3 \%$ do superior completo. No critério de renda confirmam-se os aumentos das diferenças absolutas em relação ao décimo mais rico em sete dos nove décimos abaixo dele. As discrepâncias relativas regra geral decrescem, exceto para os dois décimos inferiores da distribuição da renda, onde aumentam um pouco. Deve ser levado em conta que a composição educacional se altera no período, enquanto o décimo superior de renda, por definição, se mantém fixo. A informação educacional diz respeito a uma proporção e a um contingente de pessoas que se tornou bem maior em 2013. Além disso, podem estar envolvidos grupos com desvantagens de origem, o que tem implicações para a saúde, mas que conseguiram se beneficiar da expansão educacional do ensino superior no período. Os que possuem escolaridade superior representam um grupo mais heterogêneo em 2013 do que no passado. O fenômeno detectado de ponderável piora do quadro de saúde do segmento de escolaridade superior no Norte e no Nordeste parece refletir com mais ênfase tal situação de heterogeneidade.

Tabela 5

Variação Temporal da Probabilidade Predita de Não Ter Saúde Boa por Região e Ser ou Não Rico. Brasil, 2003-2013

\begin{tabular}{lcccccc}
\hline Região & \multicolumn{3}{c}{$10 \%$ mais Rico } & \multicolumn{3}{c}{ Não rico } \\
\hline & 2003 & 2013 & Var. & 2003 & 2013 & Var. \\
Norte & 0,140 & 0,175 & 1,250 & 0,274 & 0,330 & 1,204 \\
Nordeste & 0,126 & 0,180 & 1,429 & 0,251 & 0,337 & 1,343 \\
Sudeste & 0,084 & 0,099 & 1,179 & 0,177 & 0,206 & 1,164 \\
Sul & 0,099 & 0,115 & 1,162 & 0,204 & 0,235 & 1,152 \\
Centro-Oeste & 0,121 & 0,130 & 1,074 & 0,242 & 0,259 & 1,070 \\
Brasil & 0,103 & 0,129 & 1,252 & 0,210 & 0,255 & 1,214 \\
\hline
\end{tabular}

Fonte: Elaboração própria a partir dos microdados da PNS 2013.

A evolução do quadro de saúde entre rico e não rico é menos divergente entre as regiões. Na maioria das regiões ambos pioram numa taxa aproximada (Tabela 5). Entretanto, no Nordeste o rico tem uma evolução bem mais desfavorável, num quadro de maior deterioração para ambos os grupos, o que destaca duplamente a mudança negativa da região. O Centro-Oeste destaca-se por apresentar o menor aumento na probabilidade de ter saúde não boa para os dois polos. 
Fica claro que a escolaridade superior protege bem menos a saúde do seu detentor do que o fazia uma década antes, pois na verdade representa hoje um grupo mais heterogêneo. O processo ocorre no conjunto do país e em todas as regiões. No Nordeste a mudança no valor de saúde desse nível de escolaridade é mais dramática. O contraste entre a evolução da educação e da renda parece testemunhar igualmente o papel de bem posicional da educação cujo valor para a saúde pode estar condicionado à sua escassez. A evolução do quadro geral não é positiva, pois o estado de saúde piora para todos os grupos. A queda de desigualdade de saúde, no sentido relativo, deve-se mais ao fato daqueles que possuem vantagens socioeconômicas terem experimentado uma piora maior. Além disso, as diferenças absolutas aumentaram, pois uma taxa de deterioração menor se aplicou a uma proporção original maior de estado negativo de saúde entre os grupos socioeconomicamente em desvantagem.

\section{RELAÇÃO ENTRE AUTOAVALIAÇÃO DE SAÚDE E INDICADORES RELEVANTES}

Investigaram-se as associações entre autoavaliação da saúde, doenças crônicas e fatores de riscos à saúde para entender melhor o potencial dessa variável para caracterizar a existência de assimetrias entre grupos da população ao nível do estado médio de saúde. No morador selecionado os indicadores considerados aumentam em termos absolutos (abs.) e relativos (rel.) a probabilidade de não ter saúde boa nesta ordem de importância: doença crônica ( $21 \%$ abs.; $94 \%$ rel.); dificuldade de locomoção (22\% abs.; $90 \%$ rel.), desconforto mental (14\% abs.; $79 \%$ rel.), sedentarismo ( $8 \%$ abs.; $39 \%$ rel.), discriminação $(6 \%$ abs.; $24 \%$ rel.), tabagismo ( $4 \%$ abs.; $16 \%$ rel.) e isolamento familiar (3\% abs.; $12 \%$ rel.) (Tabela 6). Uma pessoa hipotética que acumulasse todos esses sete agravos à saúde teria uma probabilidade média de $89,2 \%$ de declarar não ter saúde boa. Mesmo num emprego no topo social, cujas condições privilegiadas minimizam as implicações dos problemas, ainda assim a pessoa teria $79,1 \%$ de probabilidade de informar uma saúde não boa. Os dados confirmam tratar-se de fatores relevantes que, neste sentido, podem estar mediando a relação entre classe social e autoavaliação de saúde.

A desigualdade de saúde entre o topo de empregos privilegiados e o resto da estrutura social, no entanto, reduz-se pouco com o controle de todos esses fatores. A discrepância absoluta entre os dois gru- 
pos cai de 13 para 12 pontos percentuais e a proporcional diminui de 1,916 para 1,801. A probabilidade fora do topo social quase não se altera, oscilando de $27,5 \%$ para $27,2 \%$, ao passo que no topo social chega mesmo a se elevar de $14,3 \%$ para $15,1 \%$, com os controles dos indicadores, revelando aí uma ausência absoluta de influência. $\mathrm{O}$ quadro configurado confirma a expectativa da investigação de que a variável de autoavaliação capta aspectos bem mais amplos da distribuição da saúde entre grupos da população.

Tabela 6

Probabilidade Predita de Saúde Não Boa por Classe e Indicadores Relevantes. Brasil, 2013

\begin{tabular}{|c|c|c|c|c|}
\hline Fatores & $\operatorname{Sim}^{*}$ & Não & Dif. Abs. & Dif. Rel. ** \\
\hline Não Topo sem indicadores & 0,274 & 0,143 & 0,130 & 1,916 \\
\hline Não Topo com indicadores & 0,272 & 0,151 & 0,121 & 1,801 \\
\hline Doença crônica & 0,440 & 0,227 & 0,213 & 1,938 \\
\hline Dificuldade de locomoção & 0,474 & 0,250 & 0,224 & 1,896 \\
\hline Desconforto mental & 0,327 & 0,183 & 0,144 & 1,787 \\
\hline Sedentarismo & 0,286 & 0,206 & 0,080 & 1,388 \\
\hline Discriminação & 0,314 & 0,253 & 0,061 & 1,241 \\
\hline Tabagismo & 0,294 & 0,253 & 0,041 & 1,162 \\
\hline Isolamento familiar & 0,289 & 0,257 & 0,032 & 1,124 \\
\hline
\end{tabular}

Fonte: Elaboração própria a partir dos microdados da PNS 2013.

* Condição referida no item binário está presente, por exemplo, não integra o topo social ou é afetado pelo fator de risco ou problema de saúde.

** Razão entre o Sim e o Não.

Foram estimados resultados utilizando a tipologia de classes completa para fazer uma análise mais circunstanciada da questão (Tabela 6). Foram controlados adicionalmente somente os cinco fatores de risco, ou seja, excluindo-se os efeitos de possuir uma doença crônica ou comprometimento de mobilidade. Nesse modelo os cinco importantes fatores aumentam a probabilidade de não ter saúde boa nesta ordem de importância: desconforto mental (17\%), discriminação $(7,7 \%)$, sedentarismo (6,5\%), tabagismo $(2,5 \%)$ e isolamento familiar $(2,3 \%)$. Os resultados mostram-se surpreendentes. Somente nas categorias destituídas de ativos, do trabalhador elementar ao excedente, diminuem as probabilidades de não ter saúde boa conforme a expectativa de redução de efeitos quando são controladas variáveis mediadoras, ou seja, os caminhos por meio dos quais os efeitos se expressam ou 
corporificam. Mesmo assim, nesses casos, ocorre uma redução bem pequena no efeito que é originalmente alto nesses estratos. Na base destituída de ativos os efeitos dos empregos em grande medida independem desses mecanismos transmissores da desvantagem socioeconômica na saúde.

Tabela 7

Probabilidade Predita de Saúde Não Boa por Classe Social, Sem e Com Controle de Fatores de Risco. Brasil, 2013

\begin{tabular}{lcc}
\hline Posições de Classe & Ajustado & + Riscos \\
\hline Topo social & 0,139 & 0,152 \\
Capitalista & 0,161 & 0,172 \\
Especialista autônomo & 0,102 & 0,123 \\
Gerente & 0,156 & 0,167 \\
Empregado especialista & 0,134 & 0,145 \\
Pequeno empregador & 0,228 & 0,242 \\
Autônomo com ativos & 0,226 & 0,230 \\
Autônomo agrícola & 0,287 & 0,285 \\
Empregado qualificado & 0,181 & 0,194 \\
Supervisor & 0,182 & 0,191 \\
Trabalhador típico & 0,249 & 0,253 \\
Trabalhador elementar & 0,321 & 0,309 \\
Autônomo precário & 0,325 & 0,310 \\
Empregado doméstico & 0,348 & 0,328 \\
Agrí́cola precário & 0,357 & 0,342 \\
Trabalhador excedente & 0,334 & 0,314 \\
\hline Fonte: Elaboração própria a partir dos microdados da PNS 2013.
\end{tabular}

Do topo social ao pequeno empregador, de modo especial, ocorrem aumentos nas probabilidades ao serem controladas a distribuição e a ação específica dos fatores de risco nas categorias. Deve-se levar em conta para situar o problema que uma pessoa com emprego no topo social que acumulasse simultaneamente os cinco fatores de risco teria uma probabilidade de $37,1 \%$ de não ter a saúde boa. Em quem não tivesse nenhum desses fatores de riscos a probabilidade cairia para $6,2 \%$. Em alguém fora do topo essa probabilidade chegaria a 54,9\% na presença de todos os fatores. Na ausência deles ela ficaria em $12,4 \%$ (dados não mostrados aqui). Trata-se de uma situação hipotética, pois a distribuição de fatores entre os grupos, como o acúmulo simultâneo de cinco tipos de riscos, naturalmente incide mais em 
quem não tem emprego privilegiado. Os fatores de risco importam para ambos os grupos, embora de modo bem diferenciado, pois as pessoas do topo possuem vantagens que contrabalançam ou minimizam parte das implicações negativas associadas à presença de situações de risco. Fatores não observados, associados ou não às variáveis independentes, podem estar gerando certo ruído nas estimativas. Entretanto, tendo em vista a não redução dos efeitos originais, como se esperaria de variáveis mediadoras, pode-se falar que considerados em conjunto os fatores de risco não responderiam pelo quadro médio geral de saúde não boa das categorias em questão.

\section{INTERAÇÕES DE CLASSE SOCIAL NA SAÚDE}

A contribuição de um fator para a saúde deve levar em conta os seus efeitos diretos e a maneira como ele interage ou altera os efeitos de outras variáveis na saúde. Classe social mostra-se relevante igualmente ao condicionar o modo como outros fatores impactam na saúde. O tratamento dos efeitos condicionais lança luz sobre a operação do fator focal e sua capacidade de ampliar ou reduzir o impacto na saúde de outras variáveis com as quais está associado.

Nesta parte do estudo será usada uma versão mais compacta da tipologia de classes na qual são definidos cinco grandes agrupamentos. O topo social é formado pelas três dimensões principais que geram privilégios, isto é, a propriedade de ativos de capital, o controle de conhecimento perito e o exercício de autoridade. O agrupamento abarca as categorias de capitalista, especialista autônomo, empregado especialista e gerente. São especificadas as posições de pequenos empregadores e de não empregadores detentores de menores ativos físicos de capital e de terra ou, dito de outro modo, os controladores de ativos de menor valor, ou generativos de menor valor econômico. Integram o grupo as categorias de pequeno empregador, autônomo com ativos e autônomo agrícola. Os empregados qualificados e os supervisores formam um segmento distinto no interior do trabalho assalariado em função de aproximações ou vínculos parciais com o exercício de autoridade e a posse de qualificações escassas. $\mathrm{O}$ trabalhador típico representa a categoria majoritária e de grande densidade social. As relações de emprego em que se encontra inserido o trabalhador típico preservam de modo mais característico as interdependências assimétricas dos processos conjugados de controle da atividade do agente e de apropriação dos resultados do trabalho. Por 
fim, visando focalizar o polo oposto, diferencia-se um bloco de posições de classe destituídas de ativos por meio de processos que levam à exclusão, à insuficiência ou à depreciação de ativos geradores de valor. Compõe esse agregado o trabalhador elementar, o autônomo precário, o empregado doméstico, o agrícola precário e o trabalhador excedente (desempregado) (Figueiredo Santos, 2010 e 2014).

Os agrupamentos mais amplos permitem estimar efeitos interativos com maior precisão. Serão consideradas as interações de classe social com a renda e a escolaridade das pessoas. Ambos os fatores têm impactos fortes na saúde e, embora estejam associados, possuem efeitos independentes um do outro. O interesse principal será saber em que medida os ganhos de saúde associados a ter mais renda e mais escolaridade variam conforme o contexto de classe. Os ganhos podem ser maiores ou menores a depender dos agrupamentos de classe.

Os efeitos interativos permitem dialogar com duas proposições ainda não suficientemente exploradas no campo de estudos. $\mathrm{O}$ efeito na saúde de uma unidade adicional de um recurso, como regra geral, tenderia a diminuir com o montante já disponível desse recurso. Em parte da literatura, no entanto, considera-se que a educação poderia não ser afetada por tal dinâmica de efeitos decrescentes (Mirowsky, Ross e Reynolds, 2000:58-59). A segunda questão diz respeito ao fato de a distribuição da saúde ser influenciada por um possível efeito de teto. Considera-se que os grupos privilegiados estão no limite do que seria factível nas condições presentes de ter uma vida mais saudável. Nessa situação as mudanças na renda, embora sejam positivas para todos, teriam consequências tendencialmente decrescentes em termos de ganhos de saúde para as posições privilegiadas que já ostentam o melhor estado de saúde. Supõe-se especialmente que as categorias na base da estrutura social no sentido amplo teriam comparativamente maiores ganhos de saúde associados a melhorias socioeconômicas (Robert e House, 2000a e b; House e Williams, 2000).

O Gráfico 1 estima os efeitos na saúde boa das interações entre classe e renda. Para efeito de apresentação dos resultados a renda foi colocada numa escala de mil reais. As diferenças absolutas estão expressas como pontos percentuais de aumento da saúde boa a cada mil reais. Foram calculados resultados separados para homem e mulher conforme o grande divisor nacional de regiões mais ou menos desenvolvidas. Os dados são apresentados de forma estratificada levando em 
conta que tanto a renda quanto a saúde variam entre os subgrupos. Nas estimativas não foram usados termos interativos para região e gênero visando preservar a precisão das estimativas de modo que os efeitos mostrados nessas diferenciações são somente aditivos. A escala de mil reais representa somente um redimensionamento (rescaling) dos dados usando uma transformação linear, nesse caso, para efeito de visualização, o que não possui as implicações de uma padronização dos dados que altere a sua distribuição. A probabilidade de um resultado é representada como um número real que varia de 0 a $1 . \mathrm{Na}$ escala usada no gráfico a probabilidade de ter boa saúde varia entre zero (.0) e 15 pontos percentuais (.15) a cada mil reais.

\section{Gráfico 1}

Diferença Absoluta na Probabilidade de Saúde Boa nas Interações de Classe e Renda. Brasil, 2013.

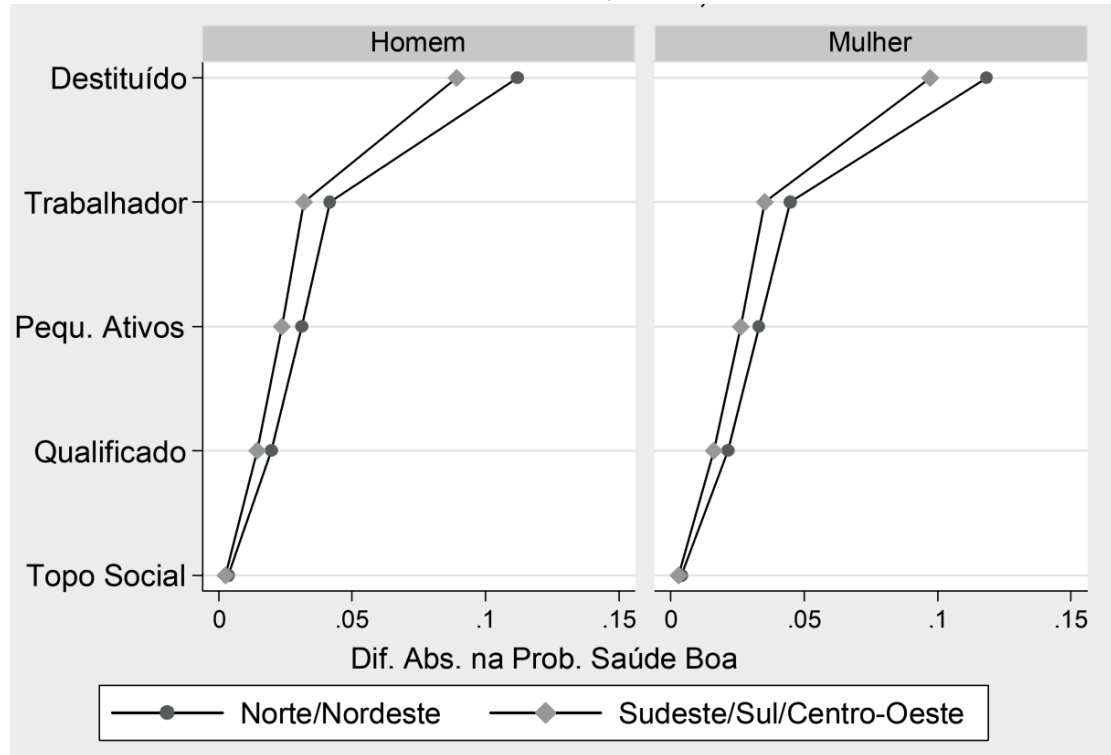

Fonte: Elaboração própria a partir dos microdados da PNS 2013.

O contraste entre o topo e o bloco destituído é bastante marcante. No topo o efeito de cada mil reais adicionais na saúde é de 0,3 pontos percentuais e fica no limite da significância estatística convencional $(0,045)^{5}$. Em todos os quatro cenários formados pela combinação de região e gênero os ganhos dos destituídos se aproximam ou superam os dez pontos percentuais a cada mil reais de mudança na renda. Quanto mais distantes do topo maiores são os ganhos das demais categorias. Os ganhos são maiores nas regiões menos desenvolvidas 
e entre as mulheres. O resultado impressiona ao revelar que ganhos adicionais de renda praticamente não alteram o estado de saúde no topo social. Foram estimadas igualmente as mudanças proporcionais no estado de saúde. Os resultados não são apresentados, pois são bastante semelhantes às diferenças absolutas, embora as duas medidas pudessem potencialmente divergir.

No Gráfico 2 são mostradas as diferenças proporcionais no logaritmo do resultado para a saúde (semielasticidade) das interações entre classe e educação. A produção de uma única estimativa média do efeito marginal pode eventualmente obscurecer diferenças nos efeitos entre os casos. O efeito médio de vários valores da educação não representa o efeito marginal real de qualquer valor particular do nível educacional. Foram então estimados os efeitos na saúde de quatro níveis educacionais mais elevados que poderiam impactar mais na saúde. Foram apresentados resultados separados para a combinação de região e gênero. $\mathrm{O}$ denominado Norte nos gráficos equivale à agregação Norte/Nordeste e Sul representa Sul/Sudeste/Centro-Oeste. Os efeitos interativos são estatisticamente simétricos. Expressam como um efeito muda sob a ação de outro fator e mostram como o efeito de classe muda o efeito da educação na saúde ou vice-versa. A aquisição da escolaridade regra geral é anterior à obtenção do emprego. Entretanto, não se trata aqui da sequência temporal. Supõe-se nas análises que os retornos de saúde da escolaridade possam variar a depender da posição de classe, pois como os empregos representam direitos e obrigações, enfeixados em papéis ou posições numa organização, aproximam-se mais da noção de contexto (estruturado e estruturante) capaz de condicionar os efeitos de outros fatores. A suposição alternativa seria que os retornos dos empregos na saúde variam a depender da escolaridade. 
Gráfico 2

Diferença Proporcional na Probabilidade de Saúde Boa nas Interações de Classe e Níveis Educacionais. Brasil, 2013.

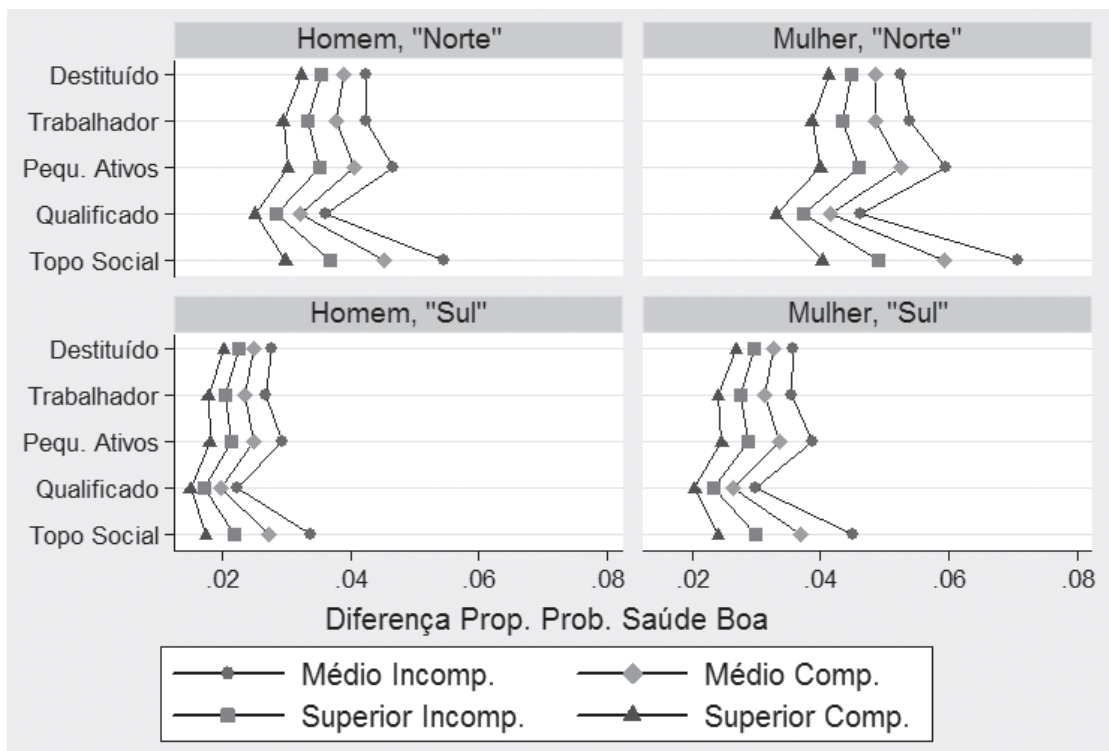

Fonte: Elaboração própria a partir dos microdados da PNS 2013.

Educação é mensurada numa escala semicredencial composta de nove itens em vez de ser medida numa métrica estrita de anos de educação completos. Inicia-se no valor zero para quem não sabe ler e escrever, depois especifica os três grandes níveis do sistema de ensino (fundamental, médio e superior) diferenciados em incompleto e completo, e termina atribuindo o valor oito ao possuidor de curso de pós-graduação stricto sensu. As variáveis entram no modelo como se fossem igualmente espaçadas ou representassem distâncias equivalentes. Foram estimadas as mudanças proporcionais no logaritmo do resultado associadas ao aumento de uma unidade educacional. Supõe-se que os ganhos obtidos ocorreriam a taxas menores numa categoria de classe cujo nível de saúde já estivesse perto do teto factível de boa saúde na atualidade.

Constata-se que os maiores ganhos de saúde estão associados aos níveis educacionais menores. Isso significa que em todos os agrupamentos de classe aqueles que possuem menos escolaridade podem ter mais ganhos de saúde ao aumentarem sua escolaridade. Entre aqueles de maior escolaridade os ganhos seriam menores, pois já não 
é possível variar tanto a escolaridade e seu impacto na saúde. Os efeitos interativos se revelam claramente no fato de os ganhos não serem equivalentes entre os grupos. No topo social os ganhos dos menores níveis de escolaridade são maiores. Logo depois estão os ganhos dos detentores de pequenos ativos de capital e terra. Quando alguém possui um melhor emprego, ou um emprego com maior potencial de gerar vantagens, porém menos escolaridade, a alteração nessa limitação educacional potencializa os benefícios de saúde. Deve-se atentar, no entanto, para o fato de que é bem menor a proporção de pessoas nessa situação no topo social. Na medida em que aumentam os níveis educacionais para superior incompleto e completo as taxas de ganhos no mesmo nível educacional vão se invertendo entre os destituídos e o topo social. No conjunto do resultado destaca-se o fato de o efeito proporcional da educação ser decrescente no topo social e decrescente no agrupamento destituído numa escala menor. Percebe-se tal processo olhando as mudanças nas distâncias e posicionamentos das linhas do gráfico em situações comparáveis. Embora a taxa de ganho seja sempre positiva ela vai se tornando menor em patamares diferentes nos polos da estrutura social conforme se move para níveis maiores de educação, o que fica claro ao se observar de forma conjugada como as mudanças nas distâncias entre as linhas afetam o posicionamento ao final da linha do superior completo.

Ao retratar as diferenças de efeitos entre os níveis educacionais conforme os agrupamentos de classe é preciso ter uma ideia dos níveis absolutos de saúde em que as diferenças entre categorias estão sendo produzidas. O Gráfico 3 apresenta as probabilidades preditas de saúde que se formam na interação entre classe e educação. Visualizam-se neste tipo de gráfico as discrepâncias absolutas entre os níveis educacionais por categorias ao se olhar para as distâncias entre as linhas. Foram estimados somente efeitos aditivos para região e gênero de modo que para tais variáveis se está vendo basicamente diferenças equivalentes entre os níveis educacionais. Em todos os quatro níveis de educação a base social está em pior situação e o topo está em melhor situação de saúde. As diferenças absolutas em pontos percentuais entre os níveis educacionais são maiores nas regiões menos desenvolvidas e entre as mulheres. A conjunção dessas duas situações faz com que o gráfico mostre maiores distâncias para as mulheres nas regiões menos desenvolvidas. 
Gráfico 3

Probabilidade Predita de Saúde Boa nas Interações de Classe e Níveis Educacionais. Brasil, 2013.

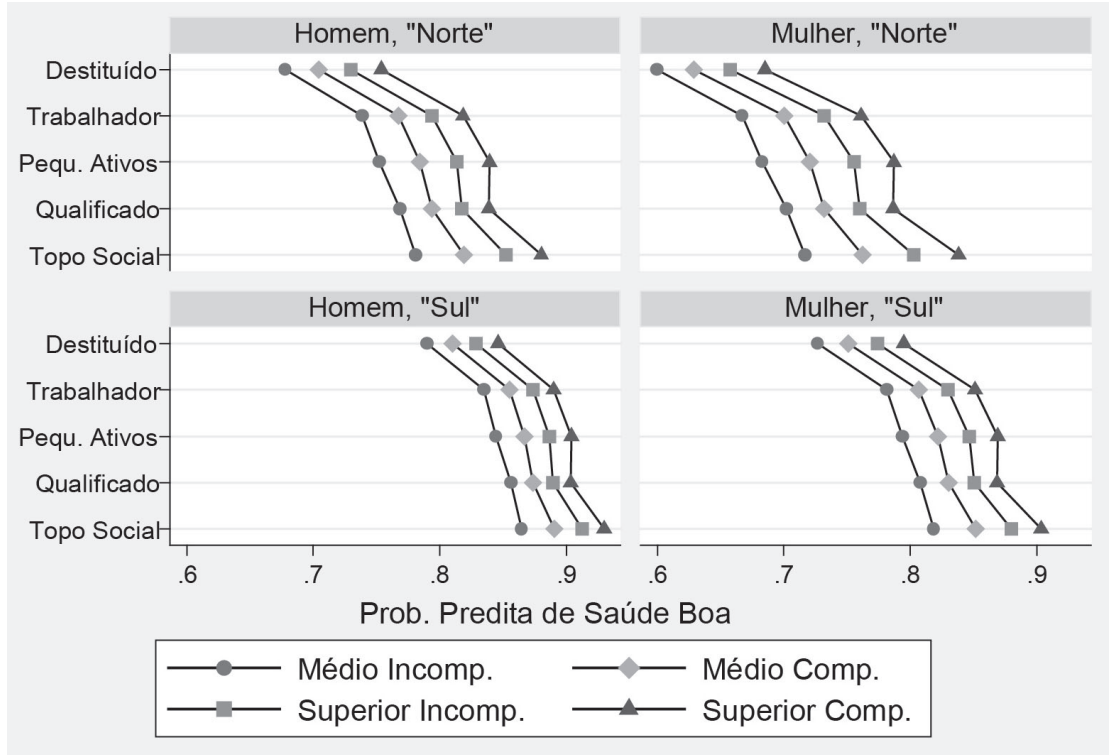

Fonte: Elaboração própria a partir dos microdados da PNS 2013.

As interações entre classe e educação representam o interesse principal nos resultados expostos. As diferenças absolutas de saúde entre os níveis educacionais são maiores no topo social. As probabilidades preditas variam de $81,5 \%$ para quem tem ensino médio incompleto a $90,0 \%$ para superior completo $(+8,5)$. Embora o topo social tenha incontestavelmente melhores níveis gerais de saúde, dentro dele os níveis educacionais geram maior variação de saúde. A maior distância está na passagem do ensino médio incompleto para completo. Não seria o caso de falar de uma maior heterogeneidade de saúde no topo social, pois nesse grupo os menores níveis educacionais são muito minoritários. Possuem ensino médio incompleto 1,4\% dos integrantes do topo social (o que está sendo estimado aqui) e 5,7\% possuem até esse nível de escolaridade. No bloco de posições destituídas a probabilidade predita de ter saúde boa varia respectivamente $72,4 \%$ a $79,2 \%(+6,8)$ entre os quatro níveis educacionais. Os empregos destituídos estabelecem limitações ou constrangimentos que comprimem estruturalmente as variações absolutas na saúde boa que podem ser produzidas pelas alterações educacionais. As nuances dos dados já vistos estão a sugerir que seria mais esclarecedor focalizar comparações entre níveis educacionais demograficamente mais salientes ou representativos de cada 
categoria. No destituído a probabilidade predita de saúde boa varia de $69,9 \%$ para $74,8 \%$ do fundamental completo ao ensino médio completo $(+4,9)$. No topo social a probabilidade de saúde boa varia de $84,8 \%$ a $90,0 \%$ do médio completo ao superior completo $(+5,2)^{6}$. Nos contrastes representativos as alterações geram consequências relativamente modestas nos dois grupos levando em conta a mudança completa de patamar educacional. Embora em ambos os polos as mudanças nas probabilidades preditas sejam sempre positivas, os ganhos vão se tornando menores em termos absolutos (as distâncias entre as linhas) conforme se move para níveis maiores de educação.

A desigualdade de saúde entre os grupos pode não se limitar à distribuição da saúde e do adoecimento. A exposição dos grupos às doenças existentes pode afetar diferenciadamente a saúde e a qualidade de vida das pessoas ${ }^{7}$. No Gráfico 4 estão estampadas as probabilidades de ter saúde não boa associadas à presença de alguma doença crônica. Registra-se a presença de alguma doença diagnosticada num leque de 13 doenças crônicas no morador aleatoriamente selecionado. O levantamento de doença diagnosticada por um médico gera um viés de seletividade na distribuição das doenças entre os grupos, gerando uma subestimação dos estratos socioeconômicos em desvantagem, pois quem procura ou tem mais acesso a serviços médicos possui mais diagnósti$\mathrm{co}^{8}$. A análise realizada aqui não focaliza propriamente a distribuição das doenças, mas os efeitos da sua presença. Entretanto, o desconhecimento da doença diagnosticada pode afetar (subestimar) a percepção pessoal da situação de saúde em quem possui menos diagnóstico provavelmente associado a desvantagens socioeconômicas. Recorre-se a interações de três níveis entre classe social, gênero e doença crônica. As diferenciações entre regiões captam somente efeitos aditivos. No modelo com interação é relaxado o constrangimento da igualdade de efeitos de se ter doença crônica. Foi incluída uma interação adicional por gênero visando modelar a possibilidade do impacto na saúde da presença de uma doença crônica ser simultaneamente diferenciado no homem e na mulher por classe social. A interação modelada entre gênero e doença faz com que se expresse o fato de homens e mulheres necessariamente não sofrerem de doenças crônicas com os mesmos padrões de comprometimentos de saúde. As interações retratam em que medida o impacto na saúde de ter doença crônica varia a depender das circunstâncias combinadas de classe social e de gênero. A variável doença crônica não capta diferenças entre as categorias no número de doenças crônicas e no tipo ou gravidade da doença. Foram estimados 
efeitos sem e com o controle adicional de outros seis agravos à saúde. São apresentadas aqui as estimativas sem os controles, pois o sentido geral dos resultados foi convergente.

Regra geral as diferenças em pontos percentuais entre as probabilidades preditas são altas, o que testemunha a consequência marcante para a percepção da saúde da existência de uma doença crônica. Existe uma variação clara e ponderável dos seus efeitos na saúde. $O$ fardo absoluto revelado pelas probabilidades preditas é bem maior na base e menor no topo social. Além de ter uma situação pior de saúde, o destituído vê a sua saúde se deteriorar ainda mais (distância entre as linhas) em termos reais com a ocorrência de uma doença crônica. Mensurações de diferenças absolutas (implícitas no gráfico) podem ser afetadas pelos patamares mais altos de prevalência no grupo do resultado que está sendo medido. As alterações produzidas pela doença crônica (distância entre as linhas) são menores no empregado qualificado/supervisor. A situação desfavorável do destituído se revela adicionalmente no fato de o impacto do adoecimento na saúde ser maior nas regiões menos desenvolvidas. O maior peso demográfico das categorias em desvantagem nessas regiões, aliado ao fato de o impacto ser mais severo nelas, faz com que a combinação de classe e território agrave o fardo de saúde de ter alguma doença crônica na população9. 


\section{Gráfico 4}

Probabilidade Predita de Saúde Não Boa nas Interações de Classe, Gênero e Doença Crônica. Brasil, 2013.

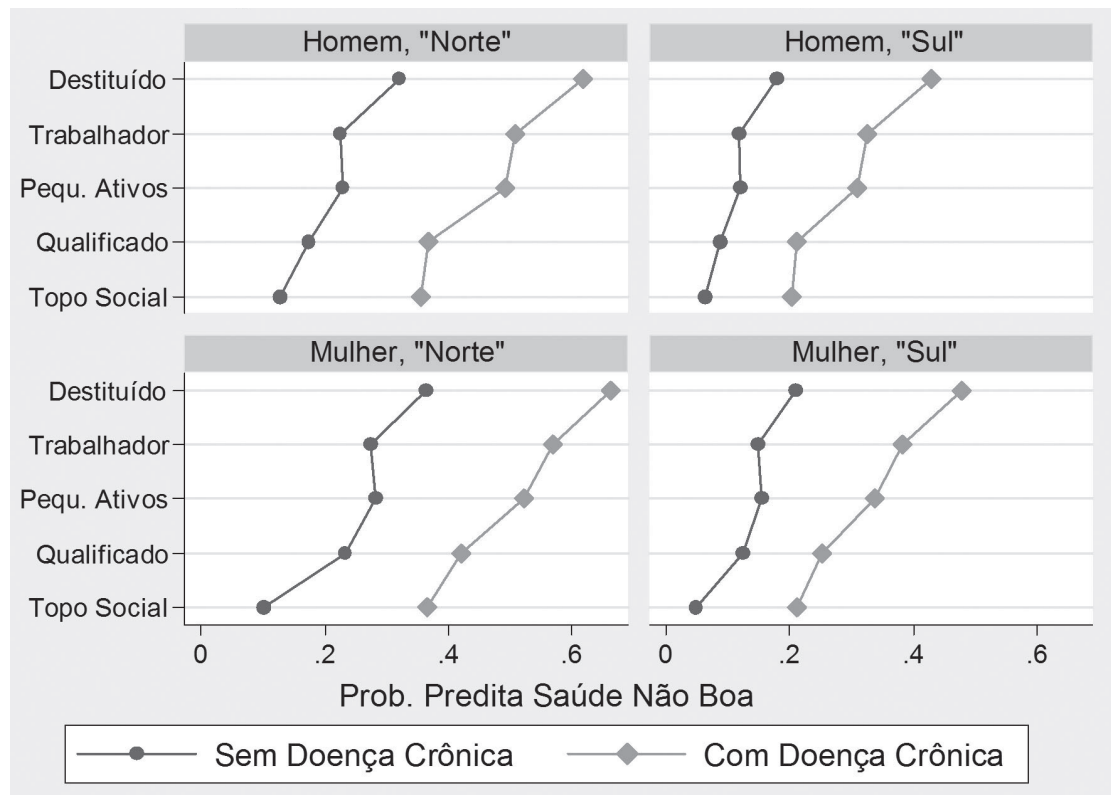

Fonte: Elaboração própria a partir dos microdados da PNS 2013.

No Gráfico 5 são retratadas as diferenças proporcionais, cujos níveis são bastante expressivos, pois a própria escala gerada capta variações no logaritmo do resultado que vão de 0,6108 para a mulher com emprego qualificado no Norte/Nordeste a 1,4948 para a mulher no topo social no Sul/Sudeste/Centro-Oeste. Em primeiro lugar cabe considerar que estão sendo vistas variações entre grupos nas diferenças internas dos efeitos nos grupos. As diferenças proporcionais são bem maiores no topo social do que no polo destituído. A diferenciação interna no topo social associada à presença de doença crônica se torna maior nas regiões mais desenvolvidas. Veja-se como exemplo o caso da mulher situada no topo social no Sul/Sudeste/Centro-Oeste. A diferença proporcional produzida no estado de saúde corresponde a uma mudança na probabilidade predita de 0,0485 sem doença crônica para 0,2105 quando presente alguma doença crônica (vide Gráfico 4). Isso equivale a uma mudança multiplicativa de 4,4583 (igual ao exponencial de 1,4948) ou a uma diferença de $346 \%$ fazendo uma aproximação pela fórmula $[\exp (\mathrm{Y})-1]^{*} 100$. O quadro observado reflete o fato de o 
patamar original de saúde não boa para quem não tem doença crônica ser muito baixo no topo social, o que amplifica a mudança proporcional em relação ao ponto de partida usado para comparação.

\section{Gráfico 5}

Diferença Proporcional na Probabilidade de Saúde Não Boa nas Interações de Classe, Gênero e Doença Crônica. Brasil 2013.

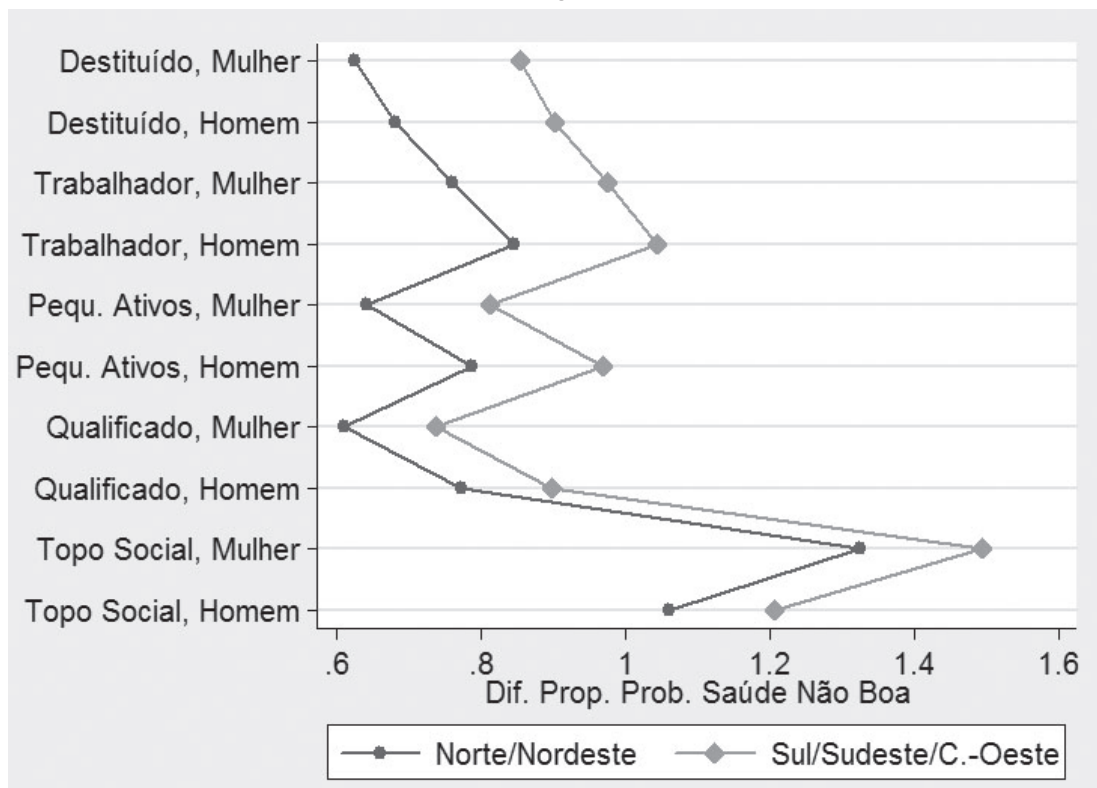

Fonte: Elaboração própria a partir dos microdados da PNS 2013.

Noções relativas e absolutas de desigualdade não são propriamente comparáveis até porque expressam ideias e métricas diferenciadas. O sentido absoluto ou relativo que se dá à noção de impacto afeta a avaliação de que grupo sofre menos ou mais danos de saúde quando possui uma doença crônica. A geração de diferenças proporcionais proeminentes no estado percebido de saúde associadas à ocorrência de doença crônica retrata uma deterioração da saúde produzida pela mudança. A importância de um fator para a saúde, no entanto, está associada tanto ao seu poder causal quanto à sua distribuição na população ou no grupo afetado. Entretanto, como o levantamento não capta adequadamente a distribuição real das doenças crônicas entre os grupos, a consideração do fator revela-se mais problemática ${ }^{10}$. O impacto fruto da combinação de distribuição e efeito da doença representaria naturalmente um fardo bastante forte e sério em termos individuais e populacionais. 


\section{DISCUSSÃO E CONCLUSÃO}

O estudo mostra o impacto da circunstância de classe social na situação de saúde das pessoas. A estrutura social hierarquiza claramente a distribuição da saúde. Capital, conhecimento perito e autoridade destacam-se como fontes de vantagens de saúde. As posições destituídas de ativos se associam às maiores desvantagens de saúde. A categoria de especialista autônomo ostenta a melhor avaliação de saúde que se impõe especialmente no contraste com as demais categorias fora do topo social. A combinação de conhecimento perito e empreendimento autônomo contribuem para manter um baixíssimo estado negativo de saúde num quadro geral que se mostra pior do que no passado. Entre as categorias que compõem o topo social não se forma um gradiente de saúde estatisticamente significativo que percorra todo o espectro socioeconômico entre os privilegiados.

A análise temporal com dois indicadores diferentes e complementares confirma uma piora de saúde para todos os grupos no período de 2003 a 2013. A renda capta de modo mais satisfatório a dimensão de resultado material enquanto a educação reflete diferenciadamente aspectos culturais e cognitivos. A depender do nível de escolaridade a piora no estado de saúde na década vai de $24,5 \%$ (sem escolaridade) a $56,6 \%$ (superior completo). Merece destaque o forte componente regional subjacente ao processo. A crescente heterogeneidade do grupo com curso superior completo, que se manifesta de modo mais marcante nas regiões menos desenvolvidas, parece afetar bastante a qualidade do indicador como marcador social para estimar desigualdades de saúde. $\mathrm{O}$ uso de décimos da renda revela uma evolução temporal menos distorcida por esse tipo de problema. No critério de renda a evolução negativa na década varia de 14,6\% (quarto décimo) a $28,9 \%$ (primeiro décimo). Entre os cinco piores desempenhos, os quatro piores estão justamente do centro para baixo da distribuição, o que relativiza bastante a queda da desigualdade relativa baseada na comparação com o décimo mais elevado. O Nordeste apresenta destacadamente a pior evolução entre ricos e não ricos. A mensuração de décimos de renda revela-se um indicador mais comparável e confiável para retratar as alterações temporais das desigualdades de saúde.

A constatação da deterioração da saúde na década deve ser ponderada por evidências adicionais e a interferência de eventuais artefatos. Os estudos disponíveis mais recentes não foram propriamente de- 
senhados para estimar a prevalência ajustada de um indicador global ou abrangente de saúde, mas oferecem certas indicações. Uma comparação temporal descritiva constata aumento da saúde ruim ou muito ruim de 3,4\% na PNAD 2003 para 4,3\% na PNS de 2013. Na mesma comparação o aumento foi de $4,4 \%$ para $6,2 \%$ no Nordeste. Norte e Nordeste não evoluem bem em doença crônica, restrição de atividades e uso de serviços de saúde. Indica-se como possível influência no resultado a maior expansão da amostra da PNS selecionada da amostra mestra do IBGE, embora no tocante ao tamanho tal amostra seja bem menor do que a da PNAD, o que afeta a precisão, pois seleciona menos domicílios por setor censitário (Viacava e Bellido, 2016:363-364). Estimativas ajustadas pelo desenho amostral, porém sem controle por modelo estatístico de variáveis como idade e outras, mostram que as declarações de saúde razoável ou ruim aumentaram significativamente de 2008 (29\%) para 2013 (32\%) (Mullachery, Silver e Macinko, 2016).

A principal variável dependente deste estudo originou-se da parte do questionário da PNS que foi projetada para dar continuidade ao Suplemento Saúde da PNAD, mantendo, inclusive, a mesma formulação e posição da questão. Entretanto, um eventual problema de artefato na comparação temporal poderia decorrer da Amostra Mestra 2010, em que a malha de setores censitários foi atualizada com os dados do Censo Demográfico. Em termos mais substantivos, os quatro indicadores usados mostram resultados convergentes, inclusive a variável educação em sua maior cobertura sem o condicionante de emprego, o que seria um modo de abordar a robustez do resultado, e variam mais no grau da tendência. Embora os dados das regiões Norte e Nordeste sofram uma evolução mais negativa, as estimativas apresentadas independem de fatores territoriais, pois controlam por região, região metropolitana e zona rural ou urbana.

A análise da desigualdade de saúde revelou que a variável dependente empregada retrata aspectos amplos da distribuição da saúde entre as categorias de classe. Embora tenham sido agregados à análise sete fatores que produzem alterações marcantes ou ponderáveis na autoavaliação saúde, todos eles não atuam enquanto conjunto como variáveis intervenientes de monta nas discrepâncias existentes entre as categorias. O quadro médio típico de saúde não boa das categorias em grande parte independe da distribuição e dos efeitos de tais fatores. As duas variáveis que formam a relação focal no estudo da 
desigualdade de saúde estariam ligadas por conexões que envolvem múltiplos e distintos aspectos. Os fatores considerados são uma parte entre outros tantos efeitos de classe social, olhando na perspectiva da variável independente, assim como se colocam entre outras tantas dimensões que compõem a percepção pessoal da saúde, vendo do lado da variável dependente.

A análise de efeitos interativos tenta entender como a classe social opera na realidade em suas conexões com outros fatores influentes. Considera-se que a conversão de determinados recursos ou condições em resultados possa ser afetada pelos contextos de classe social. De outro lado, o resultado social expresso na distribuição do estado de saúde possui características, potenciais e limites, que podem afetar a sua própria maleabilidade e a dinâmica de alterações provocadas pelos determinantes socioeconômicos.

As interações entre classe social e renda confirmam a dupla expectativa teórica indicada. Do lado da variável independente focal, os contextos de classe importam na conversão de renda em ganhos de saúde. Do lado da variável dependente, quanto melhor o estado de saúde, associado por sua vez a melhores circunstâncias materiais, menores são os patamares de ganhos. Além da marcante discrepância de ganhos associada ao contraste entre topo social e base destituída, que representa a parte principal da expectativa, a mesma lógica hierárquica de ordenamento se coloca nos demais agrupamentos de classe.

As interações entre classe social e educação sugerem que no topo social os ganhos educacionais de saúde são decrescentes em termos relativos e absolutos. Na base destituída os ganhos são decrescentes em termos relativos e absolutos numa escala menor. As transições educacionais mais elevadas de maior peso demográfico nos polos da estrutura social mostram alterações absolutas relativamente modestas na saúde considerando o nível de ganho educacional. O quadro encontrado no topo social seria mais compreensível tendo em vista o patamar de boa saúde que já foi atingido e realizado. No bloco destituído o efeito modesto da mudança educacional sinaliza o constrangimento ou a restrição de potencial colocados pelas relações e condições dos empregos. 
As interações entre classe social e doença crônica colocam um problema de especial relevância, porém ainda pouco tratado na literatura. As doenças crônicas têm uma importância crescente nos padrões de adoecimento e mortalidade da população. Além das questões relativas à incidência e à distribuição, pretendeu-se avaliar e entender melhor as possíveis variações grupais nos níveis de impacto deletério no estado de saúde das pessoas. Demanda esclarecimento em que circunstâncias e graus os fatores socioeconômicos podem afetar a capacidade de lidar ou mesmo amortecer o ônus dos problemas. As estimativas revelam que na base social destituída ocorre inegavelmente um processo mais pronunciado de deterioração absoluta do estado de saúde provocado pela doença crônica. As diferenças proporcionais, no entanto, mostram padrão inverso, pois indicam que as implicações negativas predominam no topo social. As relações características entre determinantes socioeconômicos e resultados de saúde ajudam a contextualizar melhor os termos do problema. O impacto qualitativo na saúde de um fator pode depender em parte do quão ruim a saúde já era sem a presença desse fator. Pensar a deterioração da saúde numa métrica absoluta, tendo em vista que os grupos estão previamente situados em distintos níveis de saúde, talvez reflita melhor as alterações no grau de gravidade do comprometimento de saúde produzido pela presença de um agravo adicional. Aqueles que estão em pior situação socioeconômica sofrem um fardo maior, se aproximando cada vez mais de limiares mais críticos de deterioração da saúde, justamente ao serem submetidos a um processo cumulativo de agravamento de um quadro já em si agravado.

(Recebido para publicação em 28 de novembro de 2017)

(Reapresentado em 25 de abril de 2018)

(Aprovado para publicação em 8 de abril de 2019)

\section{NOTAS}

1. A noção de invariante se aplica ao padrão hierárquico, ou seja, mais baixa a classe social, pior a saúde, o que não exclui possíveis variações contextuais dentro dessa regularidade. Entretanto, talvez fosse melhor falar de regularidade forte e generalizada, que varia em nível e manifestações a depender dos contextos.

2. Remeto o leitor para um artigo sobre a temática em que são situados os quatro principais indicadores socioeconômicos usados no estudo da desigualdade de saúde (Figueiredo Santos, 2011a).

3. Nas estimativas de efeitos interativos com a renda e a educação esse contraste é simplesmente invertido com a finalidade de focalizar a "saúde boa". Como a inversão não 
afeta em nada o resultado, a codificação como saúde boa se ajusta melhor ao argumento de variações nos retornos (ou ganhos) de saúdem a depender do grupo. Além disso, evita-se trabalhar com resultados negativos que confundem mais os leitores médios. Falar que o aumento da renda diminui mais ou menos o efeito na probabilidade de não ter saúde boa fica mais confuso.

4. Sobre este ponto levo em conta as observações do epidemiologista Clyde Schechter no fórum de discussão do programa Stata. Vide postagem: https://www.statalist.org/ forums/forum/general-stata-discussion/general/1362261-interpret-eydx-eyex-inmargins-stata.

5. Foram usados décimos de renda (20\% mais ricos entre os empregadores) para diferenciar o capitalista do pequeno empregador devido à ausência de informação sobre números de empregados na PNS 2013. Entretanto, por se tratar de categoria bem pequena $(0,7 \%)$ que integra o conjunto do topo social $(10,1 \%)$, seria bastante improvável que o resultado decorresse dessa superposição da informação de renda. Estimativa para o topo social excluindo os capitalistas mostra um efeito igualmente ínfimo $(0,4 \%)$ e bastante impreciso, com intervalo de confiança de $-0,02 \%$ a $0,9 \%$ ao nível de $99 \%$.

6. Estimativas para a educação como variável categórica no modelo mostram para o destituído um ganho de 7,0 pontos percentuais do fundamental completo ao médio completo. Do médio completo ao superior completo o aumento é de 4,8 no topo social. Entretanto, do médio incompleto ao superior completo o ganho é de 8,0 no destituído e de 12,6 no topo social. A trajetória de ganhos na comparação mais ampla para níveis maiores de escolaridade favorece o topo.

7. Embora doença crônica esteja associada à autoavaliação da saúde, a variável capta aspectos muito mais amplos do estado de saúde. As relações entre as duas não implicam num processo de endogeneidade no sentido de circularidade ou causalidade reversa. Existe exogeneidade na relação, pois a variável independente não depende da variável dependente. Doença crônica não depende da autoavaliação de saúde; ao contrário, autoavaliação de saúde depende de ter ou não doença crônica. Doença crônica seria mais um fator influente na autoavaliação da saúde, pois se manifesta como um julgamento subjetivo, sendo que a percepção e a experiência do problema afetam a avaliação. Numa estimativa mencionada neste artigo, ter uma doença crônica eleva a probabilidade de não ter saúde boa em 18 pontos percentuais em termos absolutos.

8. A distorção faz com que a distribuição de doença crônica no topo $(35,3 \%)$ se equipare ao bloco destituído (35,4\%). O trabalhador típico apresenta a menor incidência (29\%) na população adulta, sendo seguido pelo qualificado $(30,1 \%)$ e o detentor de pequenos ativos (34,3\%).

9. Ao olhar para as estimativas de diferenças absolutas e proporcionais deve-se considerar que, em certo sentido, estão sendo realizadas comparações entre duas populações hipotéticas usando dados dos casos observados. Os resultados variam a depender de dois movimentos inversos: o quanto melhora a saúde sem doença crônica e o quanto piora a saúde com doença crônica entre as populações hipotéticas.

10. As questões sobre doença crônica cobertas pelo questionário são baseadas em diagnóstico médico. Menor acesso ao sistema de saúde gera menos diagnóstico e registro, o que é afetado por fatores socioeconômicos, criando certa seletividade. 


\section{REFERÊNCIAS}

BARTLEY, Mel et al. (1999), "Understanding social variation in cardiovascular risk factors in women and men: the advantage of theoretically based measures". Social Science $\mathcal{E}$ Medicine, v. 49, n. 6, pp. 831-845.

BARTLEY, Mel. (2017), Health inequality: an introduction to theories, concepts and methods. $2^{\underline{a}}$ ed. Cambridge: Polity.

BEST, Henning; WOLF, Christof. (2015), “Logistic Regression”, in: H. Best; C. Wolf (ed.), The SAGE Handbook of Regression Analysis and Causal Inference. Los Angeles: Sage, pp. 153-171.

BORRELL, Carme et al. (2004), "Social class and self-reported health status among men and women: what is the role of work conditions, household material standards and household labor?" Social Science \& Medicine, v. 58, n. 10, pp. 1869-1887.

BRAVEMAN, Paula et al. (2005), Socioeconomic status in health research: one size does not fit all. JAMA: The Journal of the American Medical Association, v. 294, n. 22, pp. 2879-2888.

ELO, Irma T. (2009), "Class differentials in health and mortality: patterns and explanations in comparative perspective". Annual Review of Sociology, v. 35, pp. 553-572.

EUROPEAN COMMISSION. (2013), Health inequalities in the EU - Final report of a consortium. Consortium lead: Sir Michael Marmot. European Union. [24.04.2018]. Disponível em: http:/ /www.hfcm.eu/web/catalog/item/553-health-inequalities-in-the-eu-final-report-of-a-consortium-consortium-lead-sir-michael-marmot.

FIGUEIREDO SANTOS, José Alcides. (2005), “Uma classificação sócio-econômica para o Brasil". Revista Brasileira de Ciências Sociais, v. 20, n. 58, pp. 27-45.

(2010), "Comprehending the class structure specificity in Brazil". South African Review of Sociology, v. 41, n. 3, pp. 24-44.

. (2011a), "Classe social e desigualdade de saúde no Brasil". Revista Brasileira de Ciências Sociais, v. 26, n. 75, pp. 27-55.

. (2011b), "Desigualdade racial de saúde e contexto de classe no Brasil". DADOS Revista de Ciências Sociais, v. 54, n. 1, pp. 5-40.

. (2011c), "Class divisions and health chances in Brazil". International Journal of Health Services, v. 41, n. 4, pp. 691-709.

. (2014), "Esquema de classe para abordar a desigualdade de saúde no Brasil”, in F. Rosenberg (org.), Classes sociais, território e saúde: questões metodológicas e políticas. Cadernos do Itaboraí, v. 1, n. 1. Rio de Janeiro, Editora Fiocruz. Disponível em: http:/ /www. forumitaborai.fiocruz.br/node/896. Acessado em 5 de abr. 2018.

GALOBARDES, Bruna et al. (2006), "Indicators of socioeconomic position”, in: J. M. Oakes; J. S. Kaufman (eds.), Methods in social epidemiology. San Francisco: Jossey-Bass.

HANMER, Michael J.; KALKAN, Kerem Ozan. (2013), “Behind the curve: clarifying the best approach to calculating predicted probabilities and marginal effects from limited dependent variable models". American Journal of Political Science, v. 57, n. 1, pp. 263-277.

HOUSE, James et al. (1994), "The social stratification of aging and health". Journal of Health and Social Behavior, v. 35, n. 3, pp. 213-234.

DADOS, Rio de Janeiro, vol.63(1):e20180104, 2020. 


\section{Desigualdades e Interações de Classe Social na Saúde no Brasil}

HOUSE, James et al. (2005), "Continuity and change in the social stratification of aging and health over the life course". Journals of gerontology: psychological sciences and social sciences, v. 60B, Special Issue II, pp. 15-26.

HOUSE, James , WILLIAMS, David R. (2000), “Understanding and reducing socioeconomic and racial/ethnic disparities in health", in: B. D. Smedley; S. L. Syme (eds), Promoting health: intervention strategies from social and behavioral research. Washington: National Academy Press, pp. 89-131.

JYLHA, Marja. (2009), "What is self-rated health and why does it predict mortality? Towards a unified conceptual model". Social Science E Medicine, v. 69, n. 3, pp. 307-316.

. (2011), "Self-rated health and subjective survival probabilities as predictors of mortality", in: R.G. Rogers; E. M. Crimmins (eds.), International Handbook of Adult Mortality. New York: Springer, pp. 329-344.

KAM, Cindy; FRANZESE JR., Robert J. (2007), Modeling and interpreting interactive hypotheses in regression analysis: a refresher and some practical advice. Ann Arbor: University of Michigan Press.

KRIEGER, Nancy; WILLIAMS, David R.; MOSS, Nancy E. (1997), “Measuring social class in us public health research: concepts, methodologies, and guidelines". Annual Review of Public Health, v. 18, pp. 341-378.

LAHELMA, Eero. (2010), "Health and social stratification", in: W. Cockerham (ed.), The new blackwell companion to medical sociology. Oxford: Wiley-Blackwell, pp. 71-96.

LINK, G. Bruce; PHELAN, Jo. (1995), "Social conditions as fundamental causes of disease". Journal of Health and Social Behavior, extra issue, pp. 80-94.

. (2010), "Social conditions as fundamental causes of health inequalities", in: C. E. Bird et al. (orgs.), Handbook of Medical Sociology. $6^{\mathrm{a}}$ ed. Nashville: Vanderbilt University Press, pp. 3-17.

LONG, J. Scott; FREESE, Jeremy. (2014), Regression models for categorical dependent variables Using Stata. 3a ed. College Station: Stata Press.

LUTFEY, Karen; FREESE, Jeremy. (2005), “Toward some fundamentals of fundamental causality". American Journal of Sociology, v. 110, n. 5, pp. 1326-1372.

. (2011), "Fundamental causality: challenges of an animating concept for medical sociology". in: B. A. Pescosolido et al. (orgs.), Handbook of the sociology of health, illness, and healing. New York: Springer, pp. 67-81.

MANOR, Orly; MATTHEWS, Sharon; POWER, Chris. (2000), “Dichotomous or categorial responde? Analysing self-rated health and lifetime social class". International Journal of Epidemiology, v. 29, n. 1, pp. 149-157.

MARMOT, Michael; BOBAK, Martin; SMITH, George Davey. (1995), "Explanations for social inequalities in health". in: B. C. Emick et al. (eds.), Society and health. Oxford: Oxford University Press.

MARMOT, Michael; KOGEVINAS, Manolis; ELSTON, Mary A. (1987), “Social/economic status and disease". Annual Review of Public Health, v. 8, pp. 111-35. 
MIROWSKY, John; ROSS, Catherine; REYNOLDS, John. (2000), "Links between social status and health status". In: C. E. Bird; P. Conrad; A. M. Fremont (eds.), Handbook of Medical Sociology. 5a ed. Upper Saddle River: Prentice Hall, pp. 47-67.

MOOD, Carina. (2010), "Logistic regression: why we cannot do, what we think we can do, and what we can do about it". European Sociological Review, v. 26, n. 1, p. 67-82.

MULLACHERY, Pricila; SILVER, Diana; MACINKO, James. (2016), "Changes in health care inequity in Brazil between 2008 and 2013". International Journal for Equity in Health, v. 15 , p. 140 .

MULLER, Clemma J.; MACLEHOSE, Richard F. (2014), “Estimating predicted probabilities from logistic regression: different methods correspond to different target populations". International Journal of Epidemiology, v. 43, n. 3, pp. 962-970.

MUNTANDER, Carles et al. (2003), "The associations of social class and social stratification with patterns of general and mental health in a Spanish population". International Journal of Epidemiology, v. 32, n. 6, pp. 950-958.

PHELAN, Jo; LINK, G. Bruce. (2013), "Fundamental cause theory". In: W. C. Cockerham (org.), Medical sociology on the move: new directions in theory. New York: Springer, pp. 105-125.

PRAG, Patrick; SUBRAMANIAN, Subra V. (2017), "Educational inequalities in self-rated health across US States and European countries". International Journal of Public Health, v. 62 , n. 6 , pp. 709-716.

ROBERT, Stephanie; HOUSE, James. (2000a), "Socioeconomic Inequalities in Health: an enduring sociological problem". In: C. E. Bird; P. Conrad; A. M. Fremont (eds.), Handbook of Medical Sociology. 5a ed. Upper Saddle River: Prentice Hall.

(2000b), "Socioeconomic inequalities in health: integrating individual, community and societal level theory and research". In: G. Albrecht; R. Fitzpatrick; S. C. Scrimshaw (eds.), Handbook of social studies in health and medicine. London: Sage.

SMITH, Katherine E.; HILL, Sarah; BAMBRA, Clare. (2016), Health inequalities: critical perspectives. Oxford: Oxford University Press.

SZWARCWALD, Célia L. et al. (2016), "Inequalities in healthy life expectancy by Brazilian geographic regions". International Journal for Equity in Health, v. 15, p. 141.

VIACAVA, Francisco; BELLIDO, Jaime G. (2016), “Condições de saúde, acesso a serviços e fontes de pagamento, segundo inquéritos domiciliares PNS 2013". Ciência E Saúde Coletiva, v. 21, n. 2, pp. 351-370.

WARREN, John Robert; HERNANDEZ, Elaine M. (2007), “Did socioeconomic inequalities in morbidity and mortality change in the United States over the Course of the Twentieth Century?" Journal of Health and Social Behavior, v. 48, n. 4, pp. 335-351.

WILLIAMS, David R.; COLLINS, Chiquita. (1995), “US socioeconomic and racial differences in health: patterns and explanations". Annual Review of Sociology, v. 21, pp. 349-86.

WRIGHT, Erik Olin. (1997), Class counts: comparative studies in class analysis. Cambridge: Cambridge University Press. 


\section{Anexo}

Tipologia de Classes para o Brasil por Categorias Empíricas

(Critérios Originais e Aplicados à PNS 2013 pelo autor)

\section{Categorias Critérios Operacionais}

\begin{tabular}{|c|c|}
\hline $\begin{array}{l}\text { Capitalistas e } \\
\text { fazendeiros }\end{array}$ & $\begin{array}{l}\text { Critério original: Posição na ocupação de empregador; empregador não ag- } \\
\text { rícola com } 11 \text { ou mais empregados; empregador agrícola com } 11 \text { ou mais em- } \\
\text { pregados permanentes; empregador agrícola que emprega simultaneamente } \\
6 \text { ou mais empregados permanentes e } 11 \text { ou mais empregados temporários; } \\
\text { empregador agrícola com } 1.000 \text { hectares ou mais de terra, independentemente } \\
\text { do número de empregados. } \\
\text { Critério aplicado à PNS: empregador com renda do trabalho situada nos dois } \\
\text { décimos superiores da categoria de empregador [ } 20 \% \text { mais ricos]. }\end{array}$ \\
\hline $\begin{array}{l}\text { Especialistas } \\
\text { autônomos }\end{array}$ & $\begin{array}{l}\text { Critério original: Posição na ocupação de conta própria ou empregador; es- } \\
\text { pecialista de acordo com o grupo ocupacional, com até } 5 \text { empregados ou sem } \\
\text { empregados, com ou sem estabelecimento (loja, oficina, fábrica, escritório). } \\
\text { Critério aplicado à PNS: Posição na ocupação de conta própria; especialista } \\
\text { de acordo com o grupo ocupacional. } \\
\text { Códigos COD (variável E01201): 2120,2521,2522,2523,2529,2511,2512,2513, } \\
\text { 2514,2519,2111,2113,2112,2114,2141,2142,2152,2144,2145,2146,2143,2149,2131,2132, } \\
\text { 2211,2261,2250,2262,2221,2264,2265,2330,2320,2310,2351,2611,2619,2612,2632,2631, } \\
2633,2634,2635,2411,2421,2422,2423,2424,2412,2413,2431,2432,2642,2643,2654,2655 \text {, } \\
2652,3153,2133,2151,2153,2161,2162,2163,2164,2165,2166,2212,2230,2266\end{array}$ \\
\hline Gerentes & $\begin{array}{l}\text { Posição na ocupação de empregado, gerente de acordo com o grupo ocu- } \\
\text { pacional, abarcando os diretores de empresas, dirigentes da administração } \\
\text { pública, administradores em organizações de interesse público (sem fins } \\
\text { lucrativos, etc.) e gerentes de produçâo, operações e de áreas de apoio. } \\
\text { Códigos COD (variável E01201): } \\
\text { 110,411,511,1111,1112,1113,1114,1120,1211,1212,1213,1219,1221,1222,1223,1311, } \\
\text { 1312,1321,1322,1323,1324,1330,1341,1342,1343,1344,1345,1346,1349,1411, } \\
\text { 1412,1421,1420,1431,1439 }\end{array}$ \\
\hline $\begin{array}{l}\text { Empregados } \\
\text { especialistas }\end{array}$ & $\begin{array}{l}\text { Posição na ocupação de empregado, especialista de acordo com o grupo ocupa- } \\
\text { cional, incluindo as profissões credenciadas, as profissões de menor poder profis- } \\
\text { sional e os professores do ensino médio e profissional com formação superior. } \\
\text { Códigos COD (variável E01201): mesmos de especialista autônomo. }\end{array}$ \\
\hline \multicolumn{2}{|r|}{$\begin{array}{l}\text { Tipologia de Classes para o Brasil por Categorias Empíricas } \\
\text { (Critérios Originais e Aplicados à PNS } 2013 \text { pelo autor) (cont.) }\end{array}$} \\
\hline
\end{tabular}




\section{Categorias Critérios Operacionais}

\begin{tabular}{ll}
\hline & Critério original: posição na ocupação de empregador; empregador não \\
Pequenos & agrícola que ocupa de 1 a 10 empregados; empregador agrícola com 3 a 10 \\
empregadores & empregados permanentes, desde que não empregue simultaneamente de 6 a \\
& 10 empregados permanentes e 11 ou mais empregados temporários. \\
& $\begin{array}{l}\text { Critério aplicado à PNS: empregador com renda do trabalho situada nos oito } \\
\text { décimos inferiores da categoria de empregador [80\% mais pobres]. }\end{array}$ \\
\hline
\end{tabular}

Critério original: posição na ocupação de conta própria com atividade de natureza não agrícola, cujo empreendimento ou titular possui uma ou mais das seguintes condições: estabelecimento (loja, oficina, fábrica, escritório, banca de jornal ou quiosque), veículo automotor (táxi, caminhão, van, etc.) usado para

Autônomos trabalhar ou ocupação qualificada no emprego principal.

com ativos Códigos COD (variável E01201) para autônomo com ativos de qualificação: mesmos de empregado qualificado.

Critério aplicado à PNS para ativos de capital: conta própria com atividade de natureza não agrícola com renda situada nos três décimos superiores da categoria [30\% mais ricos].

Critério original: posição na ocupação de conta própria com atividade

Autônomos em empreendimento do ramo que compreende a agricultura, silvicultura, agrícolas pecuária, extração vegetal, pesca e piscicultura.

Critério aplicado à PNS: conta-própria na atividade agrícola com renda do trabalho situada nos cinco décimos superiores da categoria [50\% mais ricos].

Posição na ocupação de empregado, empregado qualificado de acordo com 0 grupo ocupacional, abarcando os técnicos de nível médio nas diversas áreas, professores de nível médio ou formação superior no ensino infantil, fundamental e profissional, professores em educação física e educação especial. Códigos COD (variável E01201):

Empregados $\quad 2263,2342,2341,3423,2352,2621,2641,2656,2653,2651,2636,3116,3134,3112,3113,3114$, qualificados $\quad 3115,3135,3117,3118,3141,3142,3143,3255,3257,3221,3222,2267,3254,3251,3214,3240$, $3211,3212,3213,3313,3314,3341,3355,3312,3322,3323,3324,3331,3315,3321,3334,3311$ $3431,3521,5241,3422,3421,4211,5111,5113,7232,2222,2240,2269,2353,2354,2355,2433$, 2434,2622,2659,3111,3119,3131,3132,3133,3139,3151,3152,3154,3155,3230,3252,3259, $3332,3333,3342,3343,3344,3351,3352,3353,3354,3359,3432,3433,3434,3511,3512,3513$, 3514,3522

Supervisores

Posição na ocupação de empregado, supervisor, chefe, mestre ou contramestre de acordo com o grupo ocupacional.

Códigos COD (variável E01201): 3121,3122,3123,5222,5151 
Tipologia de Classes para o Brasil por Categorias Empíricas (Critérios Originais e Aplicados à PNS 2013 pelo autor) (cont.)

\section{Categorias Critérios Operacionais}

Posição na ocupação de empregado, trabalhador em reparação e manutenção mecânica, ferramenteiro e operador de centro de usinagem; trabalhador de semirrotina na operação de instalações químicas, petroquímicas e de geração e distribuição de energia; trabalhador de semirrotina em serviços administrativos, comércio e vendas; trabalhador de rotina na operação de máquinas e montagem na indústria; trabalhador de rotina em serviços administrativos, comércio e vendas.

\section{Códigos COD (variável E01201):}

Trabalhadores 210,412,512,2356,2359,4110,4120,4131,4311,4213,4321,4322,4411,4412,4212,4214,4224, típicos $4226,4223,4222,5244,4227,5112,5152,5120,5131,5132,5151,5153,5141,5142,5163,5663$, $5161,8157,5411,5414,5168,5223,5230,5242,5243,5211,5212,8341,8111,8112,8113,8114$, 8342,7111,7112,7114,7411,7412,7413,7124,7121,7125,7123,7122,7131,7222,7223,7224, $8121,7221,7211,7113,7115,7119,7126,8122,7214,7212,7213,7215,8211,7127,7421,8212$, 7422,7311,7312,7313,7315,7314,8151,8152,8154,8155,8153,7532,7533,7536,8156,7534, 7535,7321,7322,7318,7522,7521,7523,8172,7541,8343,8344,8321,8322,8331,8332,8311, $8350,8312,8183,8131,8141,8142,8171,8143,7516,7515,7511,7514,7513,7512,8182,7233$, $7231,7234,3253,3256,3258,3259,3339,3411,3412,3413,3435,4132,4221,4225,4229,4312$, 4313,4323,4413,4414,4415,4416,4419,5164,5165,5169,5245,5246,5249,5311,5312,5321, $5322,5329,5412,5413,5419,6111,6112,6114,6121,6122,6123,6129,6130,6210,7132,7133,7316$, 7317,7319,7323,7531,7542,7543,7544,7549,8132,8159,8160,8181,8189,8219

Posição na ocupação de empregado, trabalhador com tarefas de trabalho bastante elementares na indústria e nos serviços, como ajudantes de obras, trabalhadores elementares na manutenção de vias públicas, faxineiros, lixeiros

Trabalhadores e carregadores de carga; trabalhadores manuais agrícolas, garimpeiros e elementares salineiros, exclusive os trabalhadores na mecanização agrícola, florestal e drenagem.

Códigos COD (variável E01201):

9112,9213,9211,9214,9212,9215,9216,6221,6224,6225,9313,9331,9332,9333,9312 ,9121,9122,9123,9129,9311,9321,9329,9334,9411,9412,9510,9520,9611,9612,961 $3,9621,9622,9623,9624,9629$

Tipologia de Classes para o Brasil por Categorias Empíricas (Critérios Originais e Aplicados à PNS 2013 pelo autor) (cont.)

\section{Categorias Critérios Operacionais}


Critério original: posição na ocupação de conta-própria e empreendimento ou titular sem a posse de nenhuma das seguintes condições: estabelecimento (loja, oficina, fábrica, escritório, banca de jornal ou quiosque), veículo automotor (táxi, Autônomos caminhão, van etc.) usado para o trabalho ou ocupação qualificada no emprego precários principal; posição na ocupação de trabalhador na produção do próprio consumo; posição na ocupação de trabalhador na construção para o próprio uso. Critério aplicado à PNS: conta-própria em atividade não agrícola com renda do trabalho situada nos sete décimos inferiores da categoria [70\% mais pobres].

Empregados Posição na ocupação de trabalhador doméstico, com ou sem carteira de domésticos trabalho assinada.

Critério original: conta-própria na atividade agrícola que controla terra pouca ou insuficiente (menos de 2 hectares), ou na condição de posseiro não tem 0 Agrícolas domínio legal sobre a sua posse, ou vê-se compelido a vender a totalidade precários (ou maior) parte da sua produção principal para o consumidor direto em mercados meramente locais.

Critério aplicado à PNS: conta-própria na atividade agrícola com renda do trabalho situada nos cinco décimos inferiores da categoria [50\% mais pobres].

Critério original: os trabalhadores excedentes são integrados pelos desempreTrabalhadores gados no sentido lato. excedentes Operacionalização na PNS: desempregado que procurou trabalho no período de referência de 30 dias. Variável E022=1 


\section{RESUMO}

\section{Desigualdades e Interações de Classe Social na Saúde no Brasil}

O artigo investiga as relações entre classe social e desigualdade de saúde no Brasil usando dados da PNS 2013. Por meio de modelos logísticos, probabilidades preditas e efeitos marginais médios são estimados na autoavaliação da saúde. Demonstra-se o papel destacado da estrutura de classes na hierarquização da distribuição da saúde. A análise temporal com dois indicadores socioeconômicos confirma uma piora de saúde para todos os grupos no período de 2003 a 2013. Na década ocorre certa queda da desigualdade proporcional e aumento da desigualdade absoluta. As relações da autoavaliação da saúde com indicadores de saúde mostram que a variável retrata aspectos amplos da distribuição da saúde entre as categorias de classe. Os contextos de classe importam na conversão de renda em ganhos de saúde: quanto melhores são as circunstâncias de classe e o estado preexistente de saúde, tanto menores são os retornos de saúde das elevações de renda. Em transições educacionais representativas as melhoras educacionais geram alterações relativamente modestas na saúde no topo e na base da estrutura social. Nas posições de classe destituídas ocorre um processo mais pronunciado de deterioração absoluta do estado de saúde provocado pela presença de doença crônica.

Palavras-chave: classe social; determinantes de saúde; desigualdade de saúde; efeitos interativos na saúde; autoavaliação da saúde

\section{ABSTRACT \\ Class Inequalities and Interactions in the Brazilian Health Sector}

The article investigates the relationships between social class and health inequality in Brazil using data from the Brazilian National Health Survey of 2013. Through logistic models, predicted probabilities and average marginal effects are estimated in the health sector self-assessment. The prominent role of class structure in the hierarchy of health distribution is demonstrated. The temporal analysis with two socioeconomic indicators confirms a worsening of health for all groups in the period from 2003 to 2013. In this decade there is a certain fall in proportional inequality and an increase in absolute inequality. The links of health self-assessment with health indicators show that the variable portrays broad aspects of health distribution among class categories. Class contexts matter in converting income to health gains: the better the class circumstances and the pre-existing state of health were, the lower will be the health gains from rising incomes. In representative educational transitions, educational improvements 
lead to relatively modest changes in the health sector at the top and bottom of the social structure. In destitute class positions, there is a more pronounced process of absolute deterioration of health caused by the presence of chronic disease.

Keywords: social class; health determinants; health inequality; interactive health effects; health self-assessment

\section{RÉSUMÉ:}

Inégalités et interactions des classes concernantes à la Santé au Brésil

L'article examine les relations entre la classe sociale et les inégalités de santé au Brésil à l'aide des données du PNS 2013. Grâce à des modèles logistiques, les probabilités prédites et les effets marginaux moyens sont estimés sur l'auto-évaluation de la Santé. On démontre le rôle prépondérant de la structure des classes dans la hiérarchie de la distribution de la Santé. L'analyse temporelle avec deux indicateurs socio-économiques confirme une dégradation de la Santé de tous les groupes entre 2003 et 2013. Au cours de la décennie, il y a une certaine baisse des inégalités proportionnelles et une augmentation des inégalités absolues. Les relations entre l'auto-évaluation de la Santé et les indicateurs de Santé montrent que la variable décrit de larges aspects de la répartition de la Santé entre les catégories de classes. Les contextes de classe sont importants pour convertir le revenu en gains de santé: meilleures sont les circonstances de classe et l'état de santé préexistant, plus les retours sur la santé des revenus augmentent. Dans les transitions éducatives représentatives, les améliorations de l'éducation génèrent des changements de Santé relativement modestes en haut et en bas de la structure sociale. Dans les classes défavorisées, il y a un processus plus prononcé de détérioration absolue de la Santé causée par la présence de maladies chroniques.

Mots-clés: classe sociale; déterminants de la santé; inégalité en matière de santé; effets interactifs sur la Santé; auto-évaluation de la santé

\section{RESUMEN}

Desigualdades e Interacciones de Clase Social en la Salud en Brasil

El artículo investiga las relaciones entre clase social y desigualdad de salud en Brasil usando datos de la Encuesta Nacional de Salud (PNS, por sus siglas en portugués) 2013. Por medio de modelos logísticos, probabilidades pronosticadas y efectos marginales medios, se estima la autoevaluación de la salud. Se demuestra el papel destacado de la estructura de clases en la jerarquización de la distribución de la salud. El análisis temporal con dos indicadores socioeconómicos 
confirma un empeoramiento de la salud para todos los grupos en el periodo de 2003 a 2013. En esa década, ocurre una caída de la desigualdad proporcional y el aumento de la desigualdad absoluta. Las relaciones de la autoevaluación de la salud con indicadores de salud muestran que la variable retrata aspectos amplios de la distribución de la salud entre las categorías de clase. Los contextos de clase importan en la conversión de renta en ganancias de salud: en la medida en que son mejores las circunstancias de clase y el estado prexistente de salud, menores son los retornos de salud de los aumentos de renta. En transiciones educativas representativas las mejoras educacionales generan alteraciones relativamente modestas en la salud en la cima y en la base de la estructura social. En las posiciones de clase denominadas destituidas, ocurre un proceso más pronunciado de deterioro absoluto del estado de salud provocado por la presencia de enfermedad crónica.

Palabras clave: clase social; determinantes de salud; desigualdad de salud; efectos interactivos en la salud; autoevaluación de la salud. 